1 Paired organic matter and pyrite $\delta^{34} \mathbf{S}$ records reveal mechanisms of carbon, sulfur, and iron cycle disruption during Ocean Anoxic Event 2

${ }^{a}$ Dept. of Earth Sciences, University of California, Santa Barbara, CA 93130 USA

$8 \quad{ }^{b}$ Dept. of Earth and Planetary Sciences, Washington University in St Louis, MO 63130

$9{ }^{c}$ Dept. of Earth and Planetary Sciences, Johns Hopkins University, Baltimore, MD 21218

$10{ }^{d}$ Dept. of Earth, Ocean, and Atmospheric Science, Florida State University, Tallahassee, FL

e Stanford Synchrotron Radiation Lightsource, Stanford University, Menlo Park, CA, 94025

*=corresponding author, raven@ucsb.edu 


\section{$15 \underline{\text { Abstract }}$}

16 The sulfur (S) isotope composition of pyrite in the sedimentary record has played an

17 important part in our understanding of the evolution of biogeochemical cycles throughout

18 Earth history. However, the kinetics of pyritization are complex and depend strongly on

19 the reactivity and mineralogy of available iron. As a second major sink for sulfide in anoxic

20 sediments, organic matter $(\mathrm{OM})$ provides essential context for reconstructing the

21 distribution and isotopic composition of environmental sulfide. To first order, roughly

22 parallel pyrite and $\mathrm{OM} \delta^{34} \mathrm{~S}$ profiles reflect changes in sulfide, while independent patterns

23 require alternative explanations, including changes in iron availability or OM

24 characteristics. We apply this framework to Ocean Anoxic Event 2 (OAE-2, 94 Mya), a

25 period of enhanced burial of reduced $\mathrm{C}$ and $\mathrm{S}$ (in OM and pyrite) that has been associated

26 with an expansion of reducing marine conditions. We present paired S-isotope records for

27 pyrite and OM along with profiles of OM S:C ratio and S redox speciation from four well-

28 characterized lithologic sections with a range of depositional environments (Pont d'Issole,

29 Cismon, Tarfaya Basin, and Demerara Rise) to reconstruct both local redox structure and

30 global mechanisms impacting the $\mathrm{C}, \mathrm{S}$ and Fe cycles around OAE-2.

32 OM sulfurization appears to be a major control on OM preservation at all four sites. Similar

33 to modern anoxic environments, there is a positive correlation between OM S:C ratios and

34 TOC concentrations for sites with more reducing conditions, implying a link between OM

35 sulfurization and burial. At consistently anoxic sites like Tarfaya Basin and Demerara Rise,

36 strongly sulfurized OM with a consistent S redox speciation and S-isotope composition

37 most likely formed rapidly in sinking particles before, during, and after OAE-2. Particle- 
38 hosted OM sulfurization may therefore have been a central mechanism facilitating the

39 massive burial of $\mathrm{OM}$ in anoxic environments during this and other periods of enhanced

40 global carbon burial. At the same time, a nearly $25 \%$ negative shift in the $\delta^{34} \mathrm{~S}$ values of

41 pyrite - but not OM - occurs at multiple, globally distributed sites prior to the onset of

42 OAE-2, indicating slower pyritization reactions that likely reflect changes in iron delivery

43 due to expanding regional or global anoxia. The combination of pyrite and organic $\mathrm{S}$

44 isotopes thus provides novel constraints on the interwoven cycles of carbon, iron, and

45 sulfur across a major carbon cycle perturbation.

\section{1. Introduction}

48 Ocean Anoxic Event 2 (OAE-2, also termed the Cenomanian-Turonian Boundary Event)

49 was a period of dynamic changes in the global carbon cycle in the Cretaceous ( $\sim 94$ million

50 years ago, Mya) during which a large portion of the global ocean experienced anoxia

51 (Ostrander et al., 2017) and associated biological turnover (Keller et al., 2008 and refs

52 therein). Expanded euxinia at the onset of the event contributed to the preservation of

53 extraordinary amounts of organic matter $(\mathrm{OM})$ in marine sediments, equivalent to roughly

54 a 60 to $80 \%$ increase in the global organic carbon burial flux maintained for $\sim 500,000$ years

55 (Owens et al., 2013; 2018; Sageman et al., 2006). This burst of ${ }^{13} \mathrm{C}$-depleted OM

56 preservation generated the characteristic positive C-isotope excursion for OAE-2 and

57 substantially drew down atmospheric $\mathrm{CO}_{2}$ (Jarvis et al., 2011). OM sulfurization can

58 enhance the preservation of total organic carbon (TOC) under anoxic conditions (Boussafir

59 et al., 1995) and has been described in TOC-rich (>10 wt\%) OAE-2 shales (Hetzel et al.,

602 2009; Kolonic et al., 2002) as well as in interbedded carbonates and marly shales with more 
61 moderate (0.2-3 wt\%) TOC (Raven et al., 2018). Still, it remains difficult to quantify the

62 impact of sulfurization on OM preservation under different environmental conditions,

63 much less to extrapolate to global fluxes of reduced sulfur and carbon burial or to estimate

64 how those fluxes might change before, during, and after OAE-2.

66 Primary considerations for determining the significance of sulfurization for TOC burial are

67 the rates and locations of S cycling in the environment. Two distinct timescales of

68 sulfurization reactions occur in modern environments: gradual sulfurization reactions

69 between bisulfide $\left(\mathrm{HS}^{-}\right)$and relatively recalcitrant $\mathrm{OM}$ occur over thousands of years under

70 strongly reducing conditions (Werne et al., 2000), and rapid sulfurization reactions

71 between polysulfides $\left(\mathrm{S}_{\mathrm{x}}{ }^{2-}\right)$ and relatively fresh, labile $\mathrm{OM}$ occur on timescales of days near

72 dynamic redox interfaces, for example in sinking marine particles (Raven et al., 2016a).

73 Rapid sulfurization has the potential to have a much more dramatic impact on TOC burial

74 because it can compete with microbial heterotrophy and preserve part of the relatively large

75 pool of fresh OM sinking out of the surface ocean (Raven et al., 2018). Still, particle-hosted

76 OM sulfurization has not been explicitly considered in analyses of TOC and sulfur burial

77 during periods of expanded oceanic anoxia like OAE-2.

79 Sulfur-isotope ratios (expressed as $\delta^{34} \mathrm{~S}$ values) are powerful tools for reconstructing the

80 sources of sulfide in the environment as well as its various potential sinks, including

81 reoxidation or precipitation as either abiogenic organic $\mathrm{S}$ or pyrite $\left(\mathrm{FeS}_{2}\right)$. Near the onset

82 of OAE-2, previously published S-isotope profiles of pyrite from multiple sites show

83 intriguing shifts toward ${ }^{34} \mathrm{~S}$-depleted values that have been interpreted in terms of changing 
84 marine sulfate concentrations (Adams et al., 2010), local chemocline position (Gomes et 85 al., 2016), and the extent of oxidative microbial sulfur cycling (Hetzel et al., 2009; Kolonic 86 et al., 2002). Although each of these hypotheses invoke changes in the distribution or $\delta^{34} \mathrm{~S}$

87 value of sulfide in the environment, OAE-2 is also associated with major changes in iron

88 cycling due to inputs from active rifting and volcanism (Owens et al., 2012), which could

89 also impact pyrite $\delta^{34} \mathrm{~S}$ values via changes in iron distributions and mineralogy. If changes

90 in the distribution or isotopic composition of sulfide are driving the shift in pyrite $\delta^{34} \mathrm{~S}$

91 values near the onset of OAE-2, we should see parallel behavior in the $\delta^{34} \mathrm{~S}$ values of

92 sulfurized OM and pyrite. If not, changes in pyrite $\delta^{34} \mathrm{~S}$ values may instead reflect changes

93 in the quantity and/or speciation of locally available iron at this time, which could impact

94 the mechanism and timing of pyrite formation in the environment.

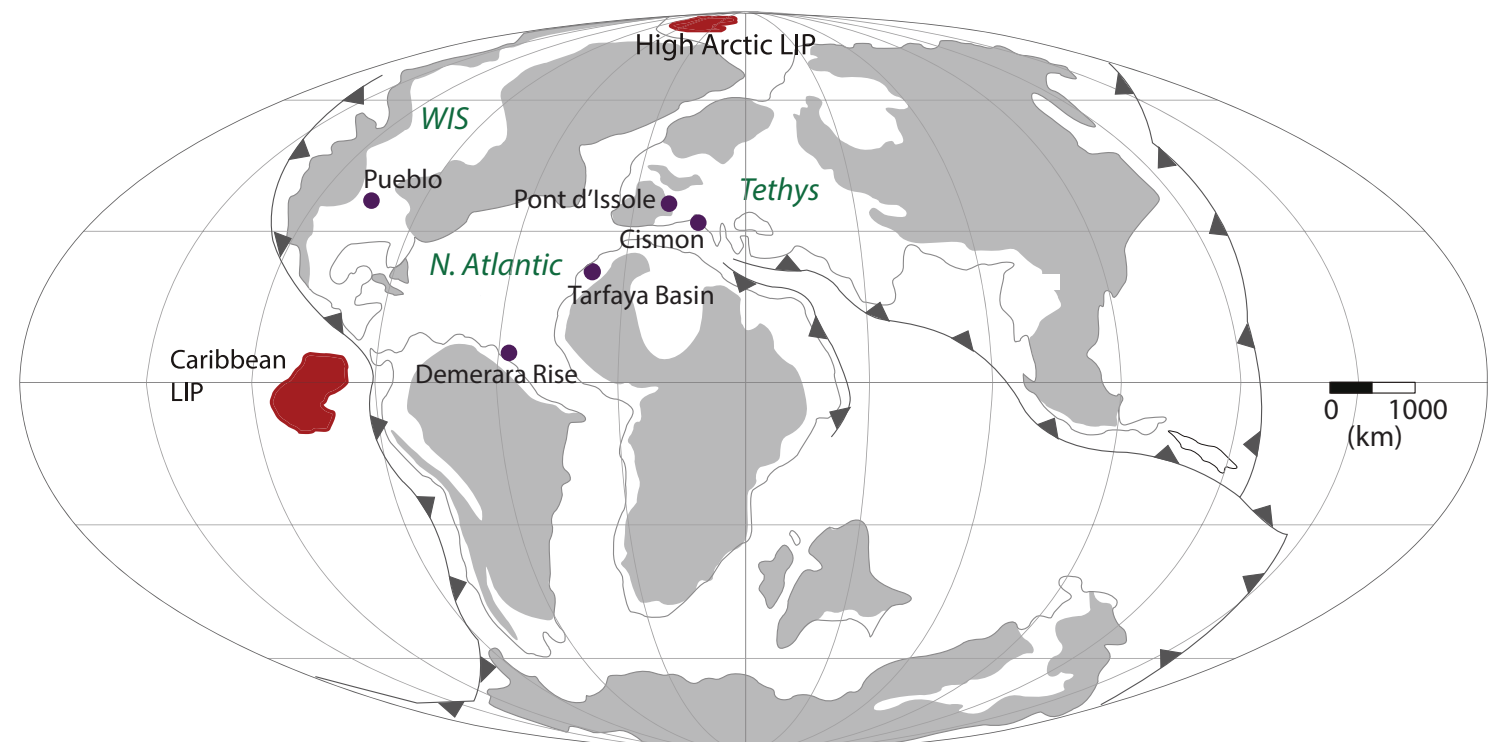

96 Fig. 1 Paleo-geography of study sites during OAE-2. Map is modified from du Vivier

97 et al. (2014) with study sections marked by purple circles. Locations of Large Igneous

98 Provinces (LIP) are also shown in red. 
100 To distinguish among these possible drivers of S-isotope variability, we present paired

101 pyrite and $\mathrm{OM} \delta^{34} \mathrm{~S}$ records alongside OM S speciation data for four OAE-2 sections

102 located in different regions of the Tethys and proto-North Atlantic Oceans (Fig. 1). Results

103 for organic S from Pont d'Issole were previously published (Raven et al., 2018); all other

104 data are new to this study. Our results indicate that the strong negative shift in pyrite $\delta^{34} \mathrm{~S}$

105 values from globally dispersed sites likely reflects a change in the quantity or speciation of

106 iron delivery to these locations. We also find evidence for a generalizable relationship

107 between sulfurization intensity and OM preservation in sediments, which implies that OM

108 sulfurization can be a primary driver of changes in $\mathrm{C}$ burial during OAE-2 and throughout

109 the Phanerozoic.

110

\section{2. Brief Methods}

112 Samples were prepared from previously sampled sections (see descriptions in Results) by 113 sequential extraction (Canfield et al., 1986; Raven et al., 2018), as detailed in the

114 Supplementary Information. Powdered rock samples were washed with deionized water,

115 lyophilized, and microwave-extracted to remove organic-solvent soluble S, including any

116 elemental S. Solids were weighed before and after acidification to estimate carbonate

117 mineral ('carbonate') abundance. Pyrite in the carbonate-free sediments was extracted by

118 treatment with hot chromium (II) chloride solution and the released sulfide, which we refer

119 to as 'pyrite', was trapped as $\mathrm{ZnS}$. Washed $\mathrm{ZnS}$ solids were oxidized to sulfate, quantified

120 by ion chromatography, and precipitated as $\mathrm{BaSO}_{4}$ for $\mathrm{S}$-isotope analysis. Remaining 121 solids after chromium reduction are considered 'organic S'. All C- and S-isotope ratio 
122 measurements were made by combustion EA-IRMS at Washington University in St Louis

123 and are reported in per mil (\%) units relative to VPDB and VCDT, respectively (see

124 Supplementary Information for analytical details). Error bars on Figures $\left( \pm 0.5 \%\right.$ for $\delta^{34} \mathrm{~S}$

125 and $\pm 0.2 \%$ for $\delta^{13} \mathrm{C}$ ) represent typical standard deviations of results for external replicates

126 (separately processed sample splits; $\mathrm{n} \geq 3$ ). To determine the bonding environment of

127 organic S, extracted sediments were analyzed by x-ray absorption spectroscopy on

128 beamline 14-3 at the Stanford Synchrotron Radiation Lightsource (SSRL) at the SLAC

129 National Accelerator Laboratory (see Supplementary Information).

130

131 3. Study Sites and Results

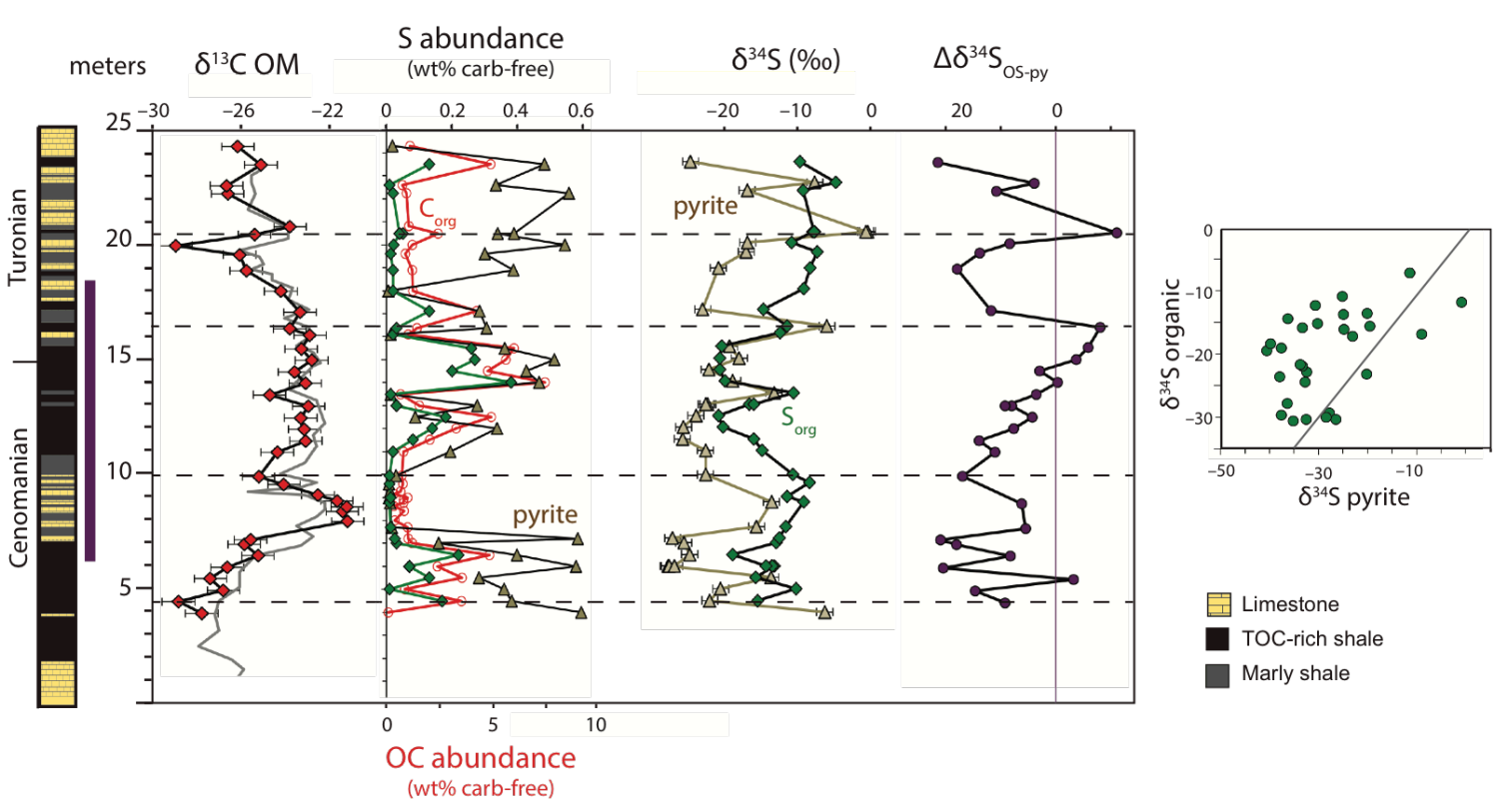

133 Fig. 2 Pont d'Issole record. The purple bar at left represents the interpreted duration of

134 OAE-2 based on the C-isotope excursion. The grey line for $\delta^{13} \mathrm{COM}_{\mathrm{OM}}$ is from Jarvis et al.

135 (2011), and lithology is from Gomes et al. (2016). Dashed horizontal lines are intended as 
136 visual aids to highlight patterns in the records. Vertical purple line for $\Delta \delta^{34}$ Sos-py shows

$137 \quad \delta^{34} S_{\text {pyrite }}=\delta^{34}$ Sos. Grey line in the right-hand panel shows a 1:1 line.

139 The Pont d'Issole section was deposited in a subsiding basin within the northern Tethys

140 Ocean $\left(\sim 30^{\circ}\right.$ N, Fig. 1) in several hundred meters of water depth with an average

141 sedimentation rate of roughly $2.4 \mathrm{~cm} / \mathrm{yr}$ (based on a 12 -m-thick C-isotope excursion

142 spanning 500 kyr; Jarvis et al., 2011). Samples were collected at outcrop in 2011. A

143 selection of mostly OM-lean carbonates from this section were analyzed previously for S-

144 isotopes in pyrite and carbonate-associated sulfate (Gomes et al., 2016). The Pont d'Issole

145 section is characterized by recurrent shifts in lithology and OM concentration between

146 relatively TOC-lean $(<0.2 \mathrm{wt} \%)$ limestones and relatively TOC-rich $(>1.0 \mathrm{wt} \%)$ shales and

147 marly shales. Our pyrite $\delta^{34}$ S profile from Pont d'Issole (Fig. 2) has many similarities to

148 the published $\mathrm{OM} \delta^{34} \mathrm{~S}$ profile (Raven et al., 2018), with comparable shifts toward lower

$149 \delta^{34} \mathrm{~S}$ values in shales before and during the OAE-2 C-isotope excursion. There are also

150 instances, however, where the S-isotope composition of pyrite behaves independently from

151 that of OM: at $5.5 \mathrm{~m}$ and $20.5 \mathrm{~m}$, for example, pyrite is locally strongly ${ }^{34} \mathrm{~S}$-enriched

152 without any parallel excursion in $\mathrm{OM} \delta^{34} \mathrm{~S}$. Additionally, the $\delta^{34} \mathrm{~S}$ offset between pyrite

153 and organic matter (Fig. 2, $\Delta \delta^{34} \mathrm{~S}_{\mathrm{OS}-\mathrm{py}}$ ) decreases systematically across the duration of the

154 C-isotope excursion from $17.4 \%$, a large but not unusual ${ }^{34}$ S-enrichment for OM relative

155 to pyrite, to $-7.9 \%$, meaning that the normal relationship between pyrite and $\mathrm{OM} \delta^{34} \mathrm{~S}$

156 values is reversed, with OM more ${ }^{34} \mathrm{~S}$-depleted than pyrite (Anderson and Pratt, 1995).

157 Illustrating the variability in $\Delta \delta^{34}$ Sos-py at Pont d'Issole, $\mathrm{OM}$ and pyrite $\delta^{34} \mathrm{~S}$ values show

158 significant spread around and to the left of the 1:1 line in the cross-plot in Fig. 2. 


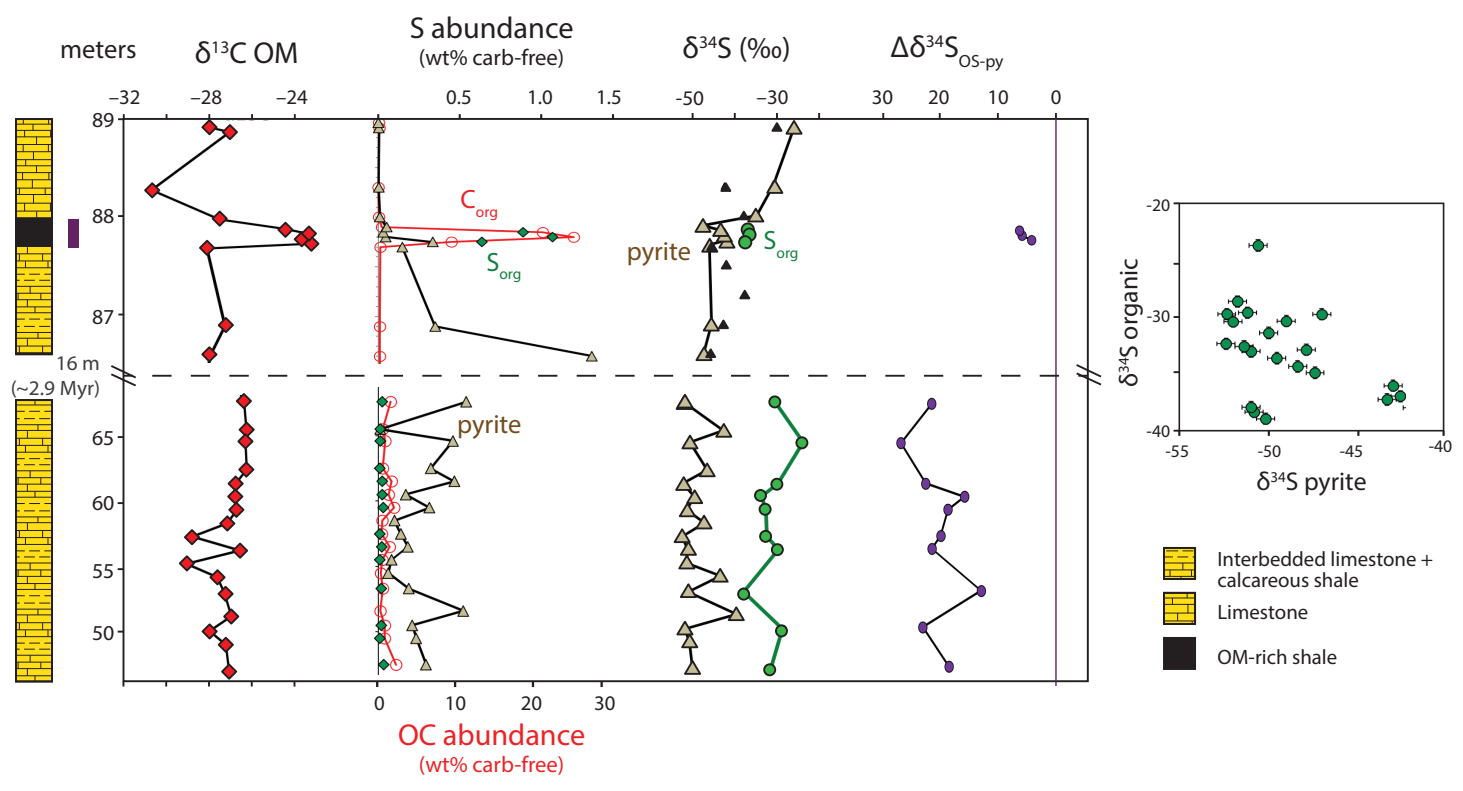

161 Fig. 3 Cismon record. The purple bar at left represents the interpreted duration of OAE-

1622 based on the $\mathrm{C}$-isotope excursion. The horizontal dashed line indicates a 16-m gap in the

163 vertical profile comprising very TOC-lean carbonates; note different scales for the upper

164 and lower panels. The duration of this gap is $\sim 2.9$ Myr based on foraminiferal biozones,

165 with an uncertainty of \pm 0.55 My for each stratigraphic interval (Bellanca et al., 1996;

166 Gambacorta et al., 2015). Lithology and published pyrite data (black triangles) are from

167 Gomes et al. (2016). Vertical purple line for $\Delta \delta^{34}$ Sos-py $_{\text {shows }} \delta^{34} \mathrm{~S}_{\text {pyrite }}=\delta^{34} \mathrm{~S}_{\text {os. }}$.

169 At Cismon, a narrow, 35 -cm-thick layer of TOC-rich $(6.5-21.4$ wt $\%)$ black shale

170 corresponds to part of the OAE-2 C-isotope excursion, although major portions of the C-

171 isotope excursion are absent due to hiatuses (Gambacorta et al., 2015; Gomes et al., 2016).

172 On either side of this lithologic unit, corresponding to the Bonarelli Layer, rocks from

173 Cismon are bedded layers of TOC-lean $(\leq 0.05 \mathrm{wt} \%)$, micritic foraminiferal limestones

174 with occasional cherts and grey shales (Bellanca et al., 1996; Gambacorta et al., 2015). 
175 Pyrite and carbonate-associated sulfate $\delta^{34} \mathrm{~S}$ values for a subset of the samples collected at

176 outcrop in 2011 were previously published for a subset of mostly TOC-lean carbonates in

177 the upper portion of the study interval (Gomes et al., 2016, Fig. 3). Here, we expand on

178 that record and add $\mathrm{OM} \delta^{34} \mathrm{~S}$ values where possible. Unfortunately, the limestones

179 immediately surrounding the black shale unit are generally too TOC-lean and silicate-rich

180 to permit spectroscopic analysis of $\mathrm{S}$ speciation or isotopic analysis of organic $\mathrm{S}$ by

181 conventional EA-IRMS. For a point of comparison with OAE-2 shales, we analyzed a

182 selection of limestones with $0.1-0.7 \mathrm{wt} \%$ TOC from lower in the section, representing 183 approximately 96 - 100 Mya (spanning a 20-meter-thick zone from $37.5 \mathrm{~m}$ above the OAE-

184 1a C-isotope excursion to $20 \mathrm{~m}$ below the onset of OAE-2, Fig. 3). In both the TOC-rich

185 layer and earlier TOC-lean limestones, OM from Cismon is strongly ${ }^{34} \mathrm{~S}$-depleted, with

$186 \delta^{34} \mathrm{~S}$ values averaging $-37 \%$ during OAE- 2 and $-38.8 \%$ in the earlier samples. Pyrite is

187 strongly ${ }^{34}$ S-depleted in the deeper, moderately TOC-rich carbonates and somewhat less

188 so in the black shale unit; pyrite $\delta^{34} \mathrm{~S}$ values for these lithologies average $-49 \%$ and -

$18942.7 \%$, respectively. The difference between the $\delta^{34} \mathrm{~S}$ values of pyrite and $\mathrm{OM}\left(\Delta \delta^{34}\right.$ Sos-

190 py) averages $20.3 \%$ in the deeper carbonates but only $5.4 \%$ in the black shale. 


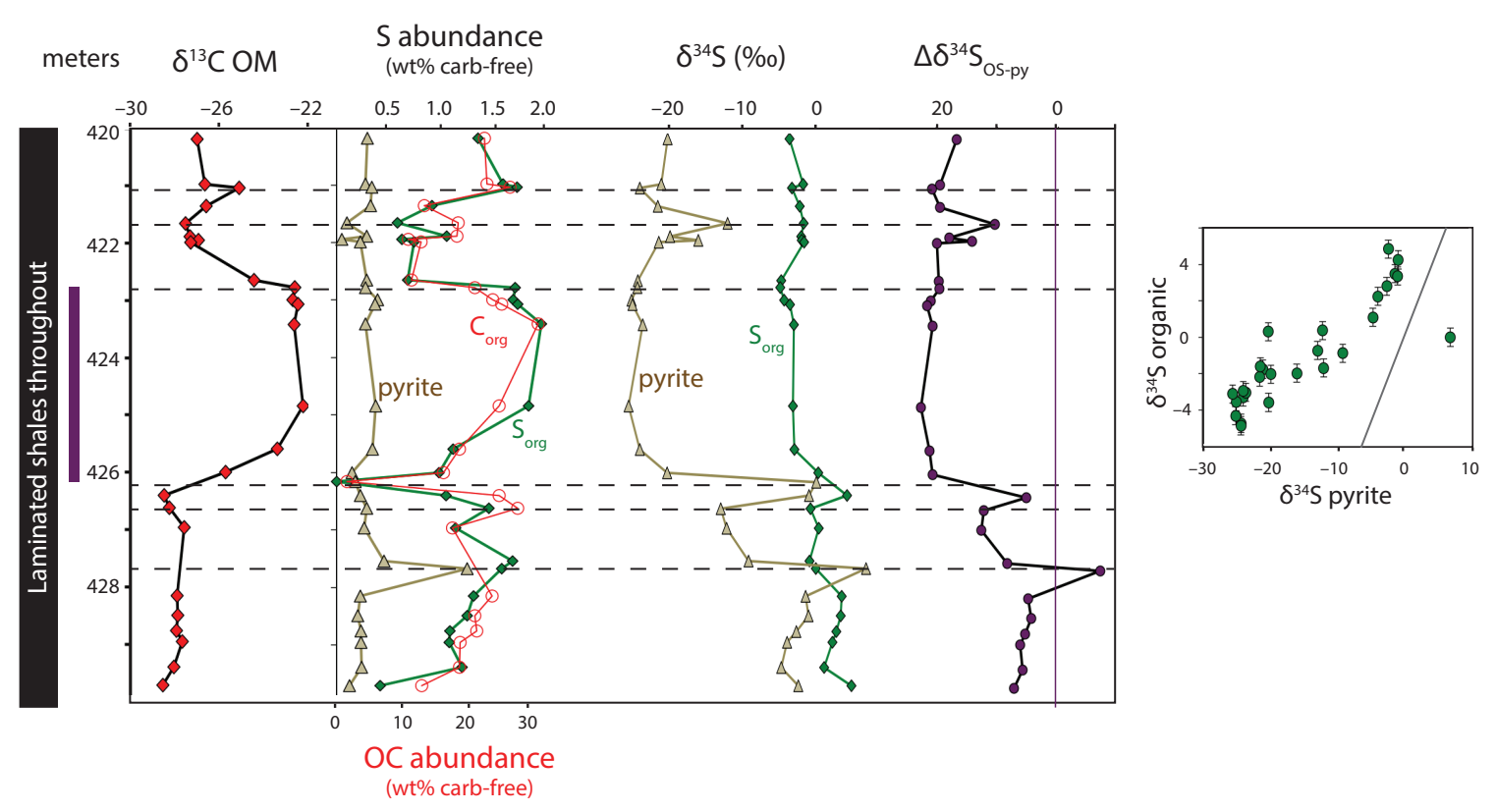

Fig. 4 Demerara Rise record. The purple bar at left represents the interpreted duration of

194 OAE-2 based on the C-isotope excursion. Dashed horizontal lines are intended as visual

195 aids to highlight patterns in the records. Vertical purple line for $\Delta \delta^{34}$ Sos-py shows $\delta^{34} S_{\text {pyrite }}$

$196=\delta^{34}$ Sos. Grey line in the right-hand panel shows a 1:1 line.

198 Sediments from Demerara Rise were deposited in the western tropical proto-North Atlantic

199 Ocean and were sampled as part of Ocean Drilling Program Leg 207 (Site 1258). Sediments

200 throughout the investigated section (with modified composite depths after Erbacher et al.,

201 2005) are generally described as laminated TOC-rich marl to black shales, with an apparent

202 average sedimentation rate of $\sim 0.8 \mathrm{~cm} / \mathrm{kyr}$ for the 4.0 -m-thick C-isotope excursion (Owens

203 et al., 2016). On a carbonate-free basis, concentrations of TOC, organic S, and pyrite S

204 show no large-scale trends across the onset and termination of the OAE (Fig. 4; Owens et

205 al., 2016). Due to reduced carbonate concentrations during the C-isotope excursion, there

206 is a perceived increase in pyrite and TOC concentrations across this interval on a whole- 
207 rock basis (Hetzel et al., 2009). Sediments are extremely OM-rich (Erbacher et al., 2005;

208 Hetzel et al., 2009), containing an average of $24 \mathrm{wt} \%$ TOC (Fig. 4; Owens et al., 2016) and

$2094.1 \mathrm{wt} \%$ organic S on a carbonate-free basis. These concentrations of organic S exceed

210 those of pyrite $\mathrm{S}$ by roughly five times. Organic matter $\delta^{34} \mathrm{~S}$ values are far less variable

211 than pyrite values; although samples after the onset of the OAE are slightly more ${ }^{34} \mathrm{~S}$ -

212 depleted, all $\mathrm{OM} \delta^{34} \mathrm{~S}$ values fall in a relatively narrow range between $-4.9 \%$ and $+4.8 \%$.

213 In contrast, pyrite $\delta^{34} \mathrm{~S}$ values decline substantially across the 2 meters of section prior to

214 the onset of OAE-2, from approximately $-3 \%$ to- $25 \%$, consistent with Hetzel et al. (2009).

215 Pyrite S-isotopes are relatively stable at these moderately ${ }^{34} \mathrm{~S}$-depleted compositions

216 throughout the OAE-2 C-isotope excursion and recover partly after the termination of the

217 event. Accordingly, $\Delta \delta^{34}$ Sos-py at Demerara Rise increases from $\sim 6 \%$ prior to OAE-2 to

$218 \sim 21 \%$ during the OAE-2 C-isotope excursion, and the slope of the data in a pyrite-OM

$219 \delta^{34} \mathrm{~S}$ crossplot is much shallower than the 1:1 line. Like at Pont d'Issole, there are also

220 instances of locally ${ }^{34}$ S-enriched pyrite in a sample without similar enrichment in organic

221 S (e.g., $427.7 \mathrm{~m})$.

222 


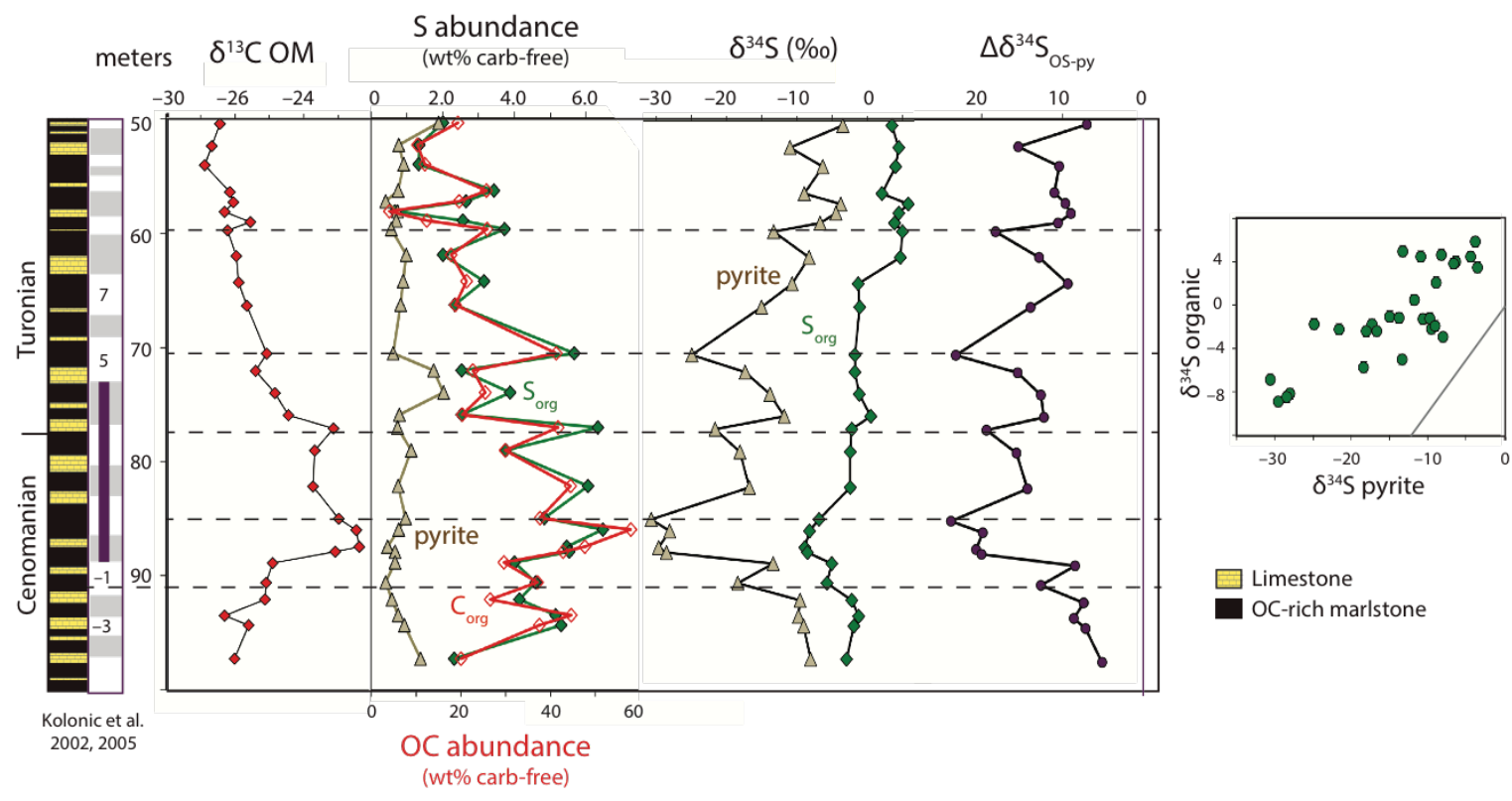

224 Fig. 5 Tarfaya Basin record. Lithology is shown at left, paired with recurrent sedimentary 225 cycles from Kolonic $(2002,2005)$. Dashed horizontal lines indicate depths with relatively 226 abundant $\mathrm{OM}$ and ${ }^{34} \mathrm{~S}$-depleted pyrite. The purple bar at left represents the interpreted 227 duration of OAE-2 based on the C-isotope excursion. Vertical purple line for $\Delta \delta^{34}$ Sos-py 228 shows $\delta^{34} S_{\text {pyrite }}=\delta^{34}$ Sos. Grey line in the right-hand panel shows a 1:1 line.

230 Tarfaya Basin sediments (sampled from Shell exploration core S75) were deposited on the 231 outer shelf of northwest Africa during a series of transgressive cycles associated with 232 rifting of the southern North Atlantic Basin. High productivity and high sedimentation rates 233 (averaging $\sim 3.3 \mathrm{~cm} / \mathrm{kyr}$ across the 16.5 -meter-thick C-isotope excursion; Kolonic et al., 234 2005) supported the formation of extremely TOC-rich black shales and somewhat less 235 TOC-rich carbonates, which alternate on apparently orbital timescales (Kolonic et al., $2362005 ; 2002$; Poulton et al., 2015; Fig. 5). This variation is also apparent in the $\delta^{34}$ S profile 237 of pyrite, which is consistent with lower resolution data from Kolonic et al. (2002) and 
238 Böttcher et al. (unpublished) as reported in Hetzel et al. (2009). Although we do not have

239 the sampling density to resolve individual orbital cycles, TOC-rich layers generally contain

240 relatively ${ }^{34}$ S-depleted pyrite, as highlighted in dashed lines in Fig. 5. On top of this regular

241 variation, the S-isotope profiles for TOC and pyrite have key similarities to those from

242 Demerara Rise. TOC and pyrite $\delta^{34} \mathrm{~S}$ values prior to the onset of the OAE are between 0

243 and $-10 \%$. By the onset of the OAE-2 C-isotope excursion, pyrite $\delta^{34} \mathrm{~S}$ values are at their

244 minimum, generally $-30 \%$. In the upper part of the core (depths $<65 \mathrm{~m}$ ), post-OAE, pyrite

$245 \delta^{34} \mathrm{~S}$ values return to pre-excursion values $\left(-5\right.$ to $-10 \%$ ). Organic matter $\delta^{34} \mathrm{~S}$ values

246 express a muted drop from near $-2 \%$ to a minimum of $-8.9 \%$ at the onset of OAE-2 and

247 a gradual increase thereafter, reaching $\sim 4 \%$ in the top of the section.
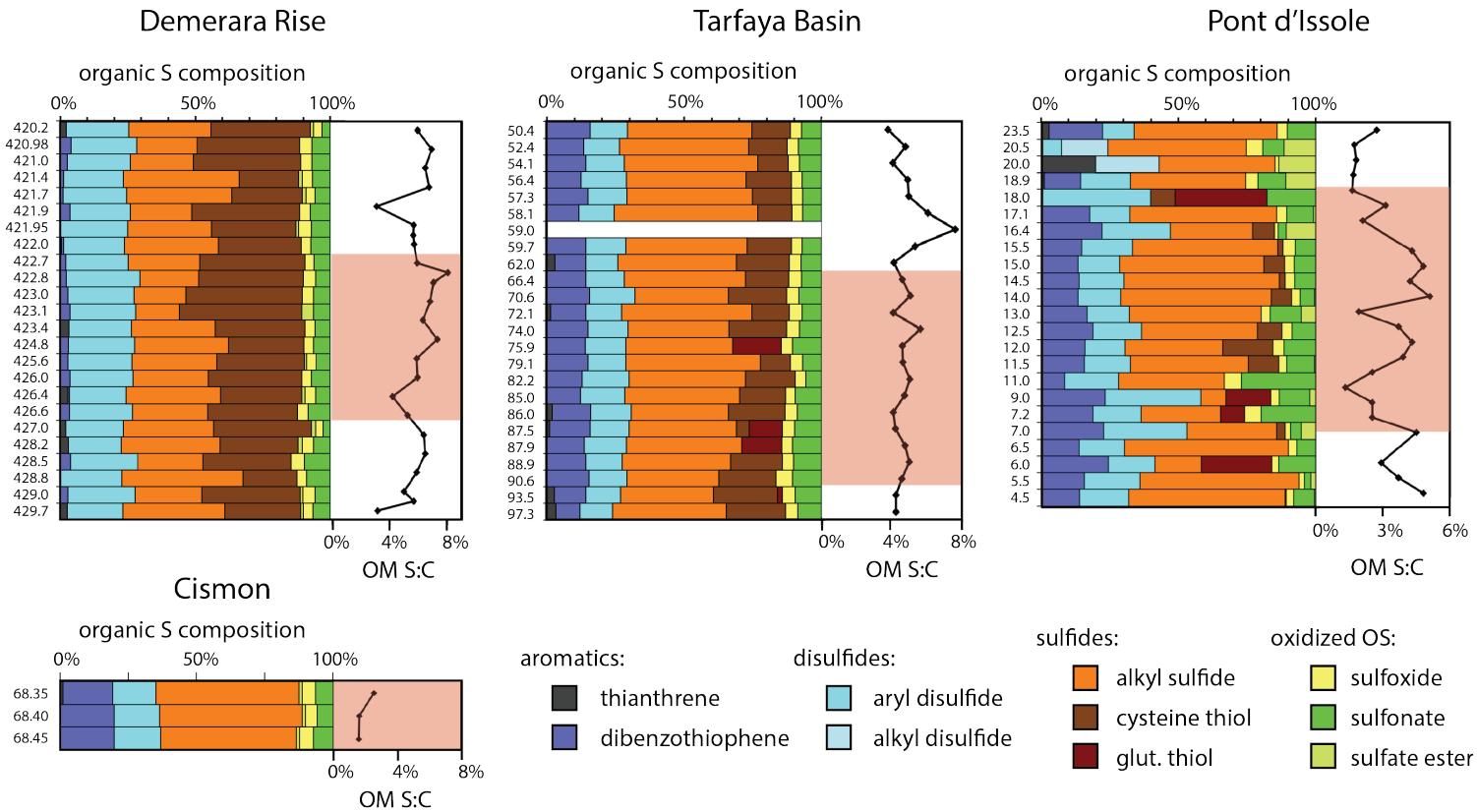

Fig. 6: Organic S speciation in organic matter. XAS and OM S:C (mol\%) ratios show

251 consistent organic S redox speciation among Demerara, Tarfaya, and Cismon samples and

252 more variable speciation associated with local environmental change in Pont d'Issole. The 
253 red shaded intervals correspond to the OAE-2 C-isotope excursion at each site. Categories

254 of reduced S structures (aromatic, disulfide, and sulfide) can be confidently distinguished,

255 but specific identifications within these groups (e.g., between sulfides and thiols) are

256 tentative.

258 X-ray absorption spectroscopy was used to quantify the relative contributions of different 259 forms of organic S to the total solvent- and acid-insoluble OM pool (Eglinton et al., 1994;

260 Vairavamurthy, 1998). At Demerara Rise and Tarfaya Basin, the speciation of organic S is

261 remarkably consistent before, during, and after the OAE-2 C-isotope excursion (Fig. 6),

262 contrasting the variation observed in the Pont d'Issole profile (Fig. 6; Raven et al., 2018).

263 Additionally, as summarized in Supplementary Table 1, the redox speciation of S-rich OM

264 (S:C $\geq 3 \%$ ) is quite comparable at all four sites, with over half of organic $\mathrm{S}$ present as alkyl

265 sulfides and substantial amounts of disulfides and sulfonates. There are subtle, yet robust,

266 site-to-site differences in organic S speciation, with Demerara Rise OM richer in disulfides

267 and leaner in aromatic S forms than OM from Cismon, Tarfaya Basin, and Pont d'Issole

268 shales. In less strongly sulfurized samples from Pont d'Issole, the relative proportions of

269 oxidized organic S forms - sulfonates and sulfate esters - are generally higher at the

270 expense of alkyl sulfides (Raven et al., 2018).

271

272 4. Discussion

273

$274 \quad$ 4.1 Organic matter S:C ratios and local redox state

275 

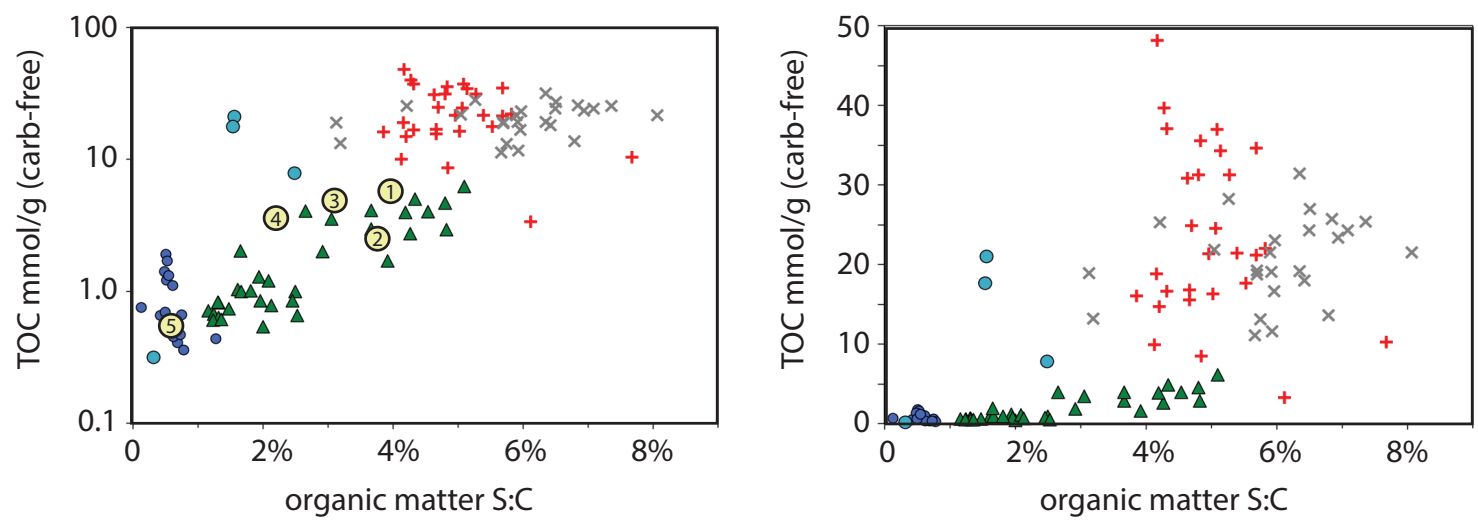

\section{Fig. 7 Global relationship between sulfurization intensity and TOC preservation.}

278 Relationships between the intensity of sulfurization (molar S:C ratio) and TOC

279 concentrations (mmol/g on a carbonate-free basis) are shown on $\log$ (left) and linear (right)

280 scales; for versions of these plots on a whole-rock basis, see Supplementary Figure 1.

281 Circled numbers on left panel refer to published values from modern environments: (1)

282 Cariaco Basin sediments (Werne et al., 2003); (2) the Peru Margin (Eglinton et al., 1994);

283 (3) the Namibian Margin (Dale et al., 2009); (4) Santa Barbara Basin sediments (Raven et

284 al., 2016b); and (5) Gulf of Lion sediments (this study; Supplementary Table 2).

286 The S:C ratio of $\mathrm{OM}$ provides an indicator of the relative intensity of sulfurization 287 reactions, with primary biomass values typically below $1 \mathrm{~mol} \%$ and strongly sulfurized 288 OM exceeding $\sim 3$ mol\% (Francois, 1987). OM S:C ratios can also be used to infer the 289 location of sulfurization (e.g., in particles sinking through the water column, at the

290 sediment-water interface, or within the sediments), which is largely a function of the redox

291 structure of the local depositional environment. Elevated OM S:C ratios require organic

292 substrates with a high density of functional groups available to react with (poly)sulfide; we 
293 refer to these groups as functionally 'sulfurizable moieties,' recognizing that certain

294 moieties may be conditionally sulfurizable, contingent on the chemical and physical

295 properties of the environment (Blair and Aller, 2012). Still, we broadly expect the highest

296 concentrations of sulfurizable moieties in surface water, where fresh marine OM is

297 relatively rich in sulfurizable aldehydes, alcohols, and conjugated double bonds (Amrani

298 and Aizenshtat, 2004). The concentration of these moieties in particulate OM will decrease

299 with depth as microbial heterotrophs degrade and consume oxygen- and energy-rich

300 components of the milieu like sugars and proteins (Hedges et al., 1999).

302 Figure 7 illustrates how the relationship between the $\mathrm{S}: \mathrm{C}$ ratio and concentration of TOC

303 for the four compiled OAE-2 sites compares with published data from modern

304 environments with different redox conditions. Bottom waters from Cariaco Basin (labeled

305 ' 1 ') are sulfidic below 250 m water depth (Werne et al., 2003); bottom waters from the

306 Peru ('2') and Namibian ('3’) Margins are $\mathrm{O}_{2}$-depleted but rarely sulfidic, with sulfidic

307 sediments (Dale et al., 2009; Eglinton et al., 1994); bottom waters in Santa Barbara Basin

308 ('4') are intermittently oxic, with sulfidic sediments; and both the bottom water and

309 shallow sediments in the Gulf of Lion (' 5 ') are oxic. Among these modern sites, S:C ratios

310 and $\mathrm{OM}$ concentrations are highest in sediments from the sulfidic Cariaco Basin and lowest

311 in sediments from the oxic Gulf of Lion. Of course, each of these sites is also affected by

312 unique chemical and physical characteristics of the environment. For example,

313 sedimentation rates are high on the Peru Margin due to the weathering of the Andes and

314 the abundance of detrital silica from diatoms, both of which presumably dilute OM

315 concentrations relative to other sites (Fig. 7). Despite this caveat, these modern sites 
316 conform to a trend toward higher $\mathrm{S}: \mathrm{C}$ ratios and higher OM concentrations associated with

317 increasingly $\mathrm{O}_{2}$-limited environments.

319 The S:C ratios and TOC concentrations for modern sites overlap with the range of data

320 from Pont d'Issole and Cismon (Fig. 7). At least in terms of these bulk parameters, OM-

321 lean carbonate rocks from both sites resemble modern deposits from the oxic Gulf of Lion,

322 and more TOC-rich shales from Pont d'Issole resemble more $\mathrm{O}_{2}$-limited sites like the Peru

323 Margin and Cariaco Basin. In a previous study that focused only on samples from Pont

324 d'Issole, positive correlations among OM S:C ratios, TOC concentrations, and OM $\delta^{34} \mathrm{~S}$

325 values were attributed to changes in local redox conditions (Raven et al., 2018), consistent

326 with these modern analogs. During more $\mathrm{O}_{2}$-limited periods at Pont d'Issole, rapid OM

327 sulfurization reactions likely generated OM with S:C ratios near 5\% in the water column

328 or near the sediment-water interface, where relatively fresh OM contains at least that

329 concentration of functionally sulfurizable moieties. During more oxic periods, gradual

330 sulfurization reactions in sediments affected older OM ( $\geq 10$ s of years) with a lower

331 concentration of sulfurizable moieties and generated $\mathrm{OM}$ with $\mathrm{S}: \mathrm{C}$ ratios closer to $2 \%$

332 (Raven et al., 2018).

334 Southern proto-North Atlantic OAE-2 samples extend the trend in Figure 7 toward even

335 greater OM concentrations and S:C ratios than those associated with bottom water anoxia

336 at Cismon, Pont d'Issole, and modern sites. We lack modern analogues for remarkable

337 hotspots of TOC burial like Tarfaya Basin, which had an outsized role in driving changes

338 in the OAE-2 C and S cycles (Kolonic et al., 2005; Sinninghe Damsté and Köster, 1998). 
339 At both Demerara Rise and Tarfaya Basin, there is abundant evidence for water column

340 euxinia and at least intermittent photic zone anoxia. Finely laminated sediments from

341 Demerara Rise (Erbacher et al., 2005) contain only occasional benthic foraminifera

342 (Friedrich et al., 2006), iron speciation documents local sulfidic conditions (Owens et al.,

343 2016), and trace metals also suggest reducing local conditions (Hetzel et al., 2009) that

344 expand globally during the event (Owens et al., 2016). At Tarfaya, an anoxic and

345 commonly sulfidic water column is evidenced by iron speciation, organic petrography, and

346 the presence of biomarkers for phototrophic sulfide oxidizing bacteria (in nearby core S13;

347 Kuypers et al., 2002; Poulton et al., 2015). Still, there is also evidence for periodic, short-

348 lived intervals of less strongly reducing conditions (Poulton et al., 2015), potentially

349 contributing to slightly lower OM S:C ratios at this site than at Demerara. In general,

350 however, reducing conditions at both southern proto-North Atlantic sites could have

351 facilitated rapid, extensive sulfurization of a large pool of fresh OM in sinking particles

352 with a high concentration of functionally sulfurizable moieties (Sinninghe Damsté and

353 Köster, 1998). We emphasize that, in contrast with prior work, our conceptual model

354 invokes near-instantaneous reactions between $\mathrm{OM}$ with some concentration of sulfurizable

355 moieties and polysulfide, wherever sulfide and oxidants are first available in the

356 environment. Polysulfide 'availability' for sulfurization will depend on microbial sulfate

357 reduction rates, oxidant availability, and competition with Fe; importantly, however, it does

358 not necessarily imply measurable free sulfide in the ('bulk') water column.

360 We can also compare OM from Demerara Rise and Tarfaya Basin with the results of 361 laboratory sulfurization experiments utilizing fresh algal biomass or model compounds. In 
362 the presence of excess polysulfides, lipids and carbohydrates sulfurize to form

363 macromolecular material in which characteristic components have S:C ratios around 2-3\%

364 (Gelin et al., 1998) and $\sim 6.7 \%$ (van Dongen et al., 2003), respectively. For dissolved

365 organic matter, bulk molar S:C ratios can apparently be much higher, reaching as much as

$36615 \%$ in recent experiments (Pohlabeln et al., 2017). Still, the average S:C ratios of (bulk,

367 particulate) OM from Tarfaya Basin (5.0\%), Demerara Rise (5.9\%), and Cismon shales

$368(5.0 \%)$ indicate that the OM sulfurizing in these environments had a concentration of

369 sulfurizable moieties similar to the constituents of fresh, carbohydrate-rich algal biomass.

370 Experimental data thus lend credence to the hypothesis that rapid, likely particle-hosted,

371 sulfurization drove OM preservation in the water columns of both Tarfaya Basin and

372 Demerara Rise.

373

374 Broadly speaking, the relationship between S:C ratio, OM preservation, and local redox 375 structure appears to be generalizable for marine environments, with the highest S:C ratios

376 and TOC concentrations supported by rapid, particle-hosted sulfurization under strongly

$377 \mathrm{O}_{2}$-limited conditions. The observation that $\mathrm{OM}$ sulfurization is an apparently major

378 control on OM burial in diverse redox settings invites parameterization and application of

379 this trend to models of carbon cycling on local to global scales and throughout the geologic 380 record.

$383 \quad \underline{4.2}$ Interpreting organic matter and pyrite $\delta^{34} \mathrm{~S}$ records 
385 To first order, the sulfur isotope compositions of pyrite and organic S reflect the $\delta^{34} \mathrm{~S}$ value 386 of sulfide and/or polysulfide in the environment where that solid phase formed, with OM 387 commonly $\sim 5-10 \%$ more ${ }^{34}$ S-enriched than coexisting pyrite (Anderson and Pratt, 1995). 388 Accordingly, S-isotope ratios - of both pyrite and sulfurized OM - provide potentially 389 powerful archives of information about the availability and distribution of sulfide in the 390 environment. Several primary factors affect the integrated (poly)sulfide $\delta^{34} \mathrm{~S}$ value 391 recorded in pyrite and $\mathrm{OM}$, including (1) the $\delta^{34} \mathrm{~S}$ value of the sulfate used in microbial 392 sulfate reduction (MSR, Fike and Grotzinger, 2008); (2) the fractionation factor associated

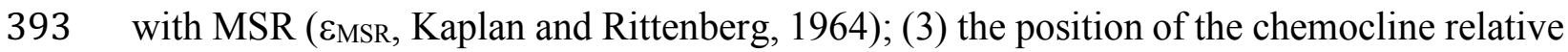
394 to diffusively 'closed' sediments (Jorgensen, 1979) and (4) the concentration of sulfate and 395 resulting depth of sulfate depletion (Adams et al., 2010). Importantly, all of these processes 396 impact the distribution and/or $\delta^{34} \mathrm{~S}$ value of (poly)sulfide in the environment and should 397 therefore impact the S-isotope composition of both pyrite and OM, generating roughly 398 parallel $\delta^{34} \mathrm{~S}$ profiles. If pyrite and $\mathrm{OM} \delta^{34} \mathrm{~S}$ profiles are not parallel, then we need to invoke 399 processes that affect these sinks differently. 

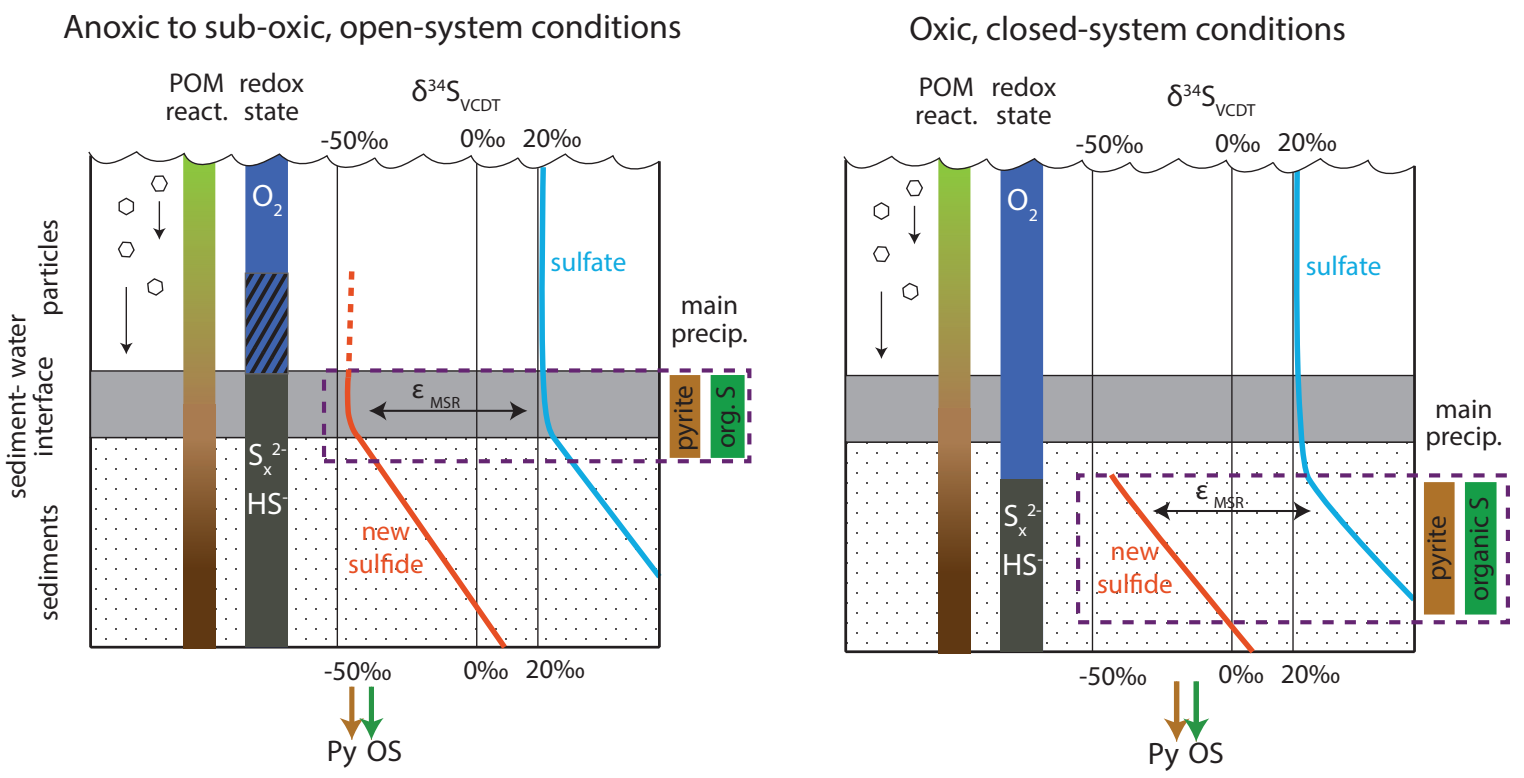

402 Fig. 8: Model for organic S and pyrite formation at Pont d'Issole and Cismon. The

403 color scale labeled "POM react." represents a generalized decline in the reactivity of

404 particulate OM with age since export from the photic zone. At left, the dashed red line and

405 hatched redox state depict differences between sub-oxic and anoxic conditions. Under

406 anoxic conditions, the zone of precipitation for pyrite and organic S would move upward

407 with the chemocline. Diagram is not to scale.

409 At Pont d'Issole, OM and pyrite $\delta^{34}$ S profiles move in roughly parallel between the TOC-

410 rich and TOC-lean layers associated with OAE-2 (Fig. 2). Accordingly, these phases

411 appear to be primarily recording changes in the $\delta^{34} \mathrm{~S}$ value or distribution of sulfide in the

412 environment. Like $\mathrm{OM} \delta^{34} \mathrm{~S}$ values at this site (Raven et al., 2018), pyrite $\delta^{34} \mathrm{~S}$ values

413 describe the extent to which sulfate was diffusively limited in sediments, shown

414 schematically in Fig. 8. Under conditions where $\mathrm{O}_{2}$ concentrations are drawn down to zero

415 at roughly the sediment-water interface (which we call 'sub-oxic' in Fig. 8), MSR in the

416 shallowest sediments can access the open-ocean pool of seawater sulfate with an 
417 unfractionated $\delta^{34} \mathrm{~S}$ value, and the resulting strongly ${ }^{34} \mathrm{~S}$-depleted sulfide from MSR is

418 recorded in both pyrite and OM. Under more 'oxic' conditions, $\mathrm{O}_{2}$ penetrates deeper in the

419 sediments and microbial sulfate reduction occurs in a diffusively sulfate-limited

420 environment. As available sulfate is consumed with some fractionation $\left(\varepsilon_{\mathrm{MSR}}\right)$, residual

421 sulfate in porewater becomes enriched in ${ }^{34} \mathrm{~S}$, and the organic and inorganic sulfur pools

422 that precipitate within such a (partially) closed system have higher integrated $\delta^{34} \mathrm{~S}$ values

423 than those formed in open systems. At Pont d'Issole, S-isotope evidence for more closed-

424 system MSR is also associated with smaller amounts of preserved OM with a lower S:C

425 ratio (Raven et al., 2018).

426

427 Both organic $\mathrm{S}$ and pyrite from Cismon black shales are strongly ${ }^{34} \mathrm{~S}$-depleted, consistent 428 with generally open-system pyrite and organic S formation during the OAE C-isotope 429 excursion. These low $\delta^{34} \mathrm{~S}$ values resemble S-isotope values observed in sediments from 430 modern sulfidic basins, which have been attributed to open-system pyritization (Lyons et 431 al., 2003). As noted by the dashed vertical red line in Fig. 8, the critical sulfidic 432 environment(s) hosting these reactions could be very shallow sediments and/or particles 433 sinking through the water column. In deeper carbonates from Cismon, OM is only weakly 434 sulfurized (S:C averaging $0.6 \mathrm{~mol} \%$ ), so the connection between dissolved (poly)sulfides 435 and the $\delta^{34} \mathrm{~S}$ value of OM is less robust. High $\Delta \delta^{34}$ Sos-pyrite values for samples with low S:C 436 ratios $(\leq 1.0 \mathrm{~mol} \%)$ could reflect contributions from detrital, biomass, or macrofaunal 437 exudate sources to organic $\mathrm{S}$ in addition to sulfurization. 

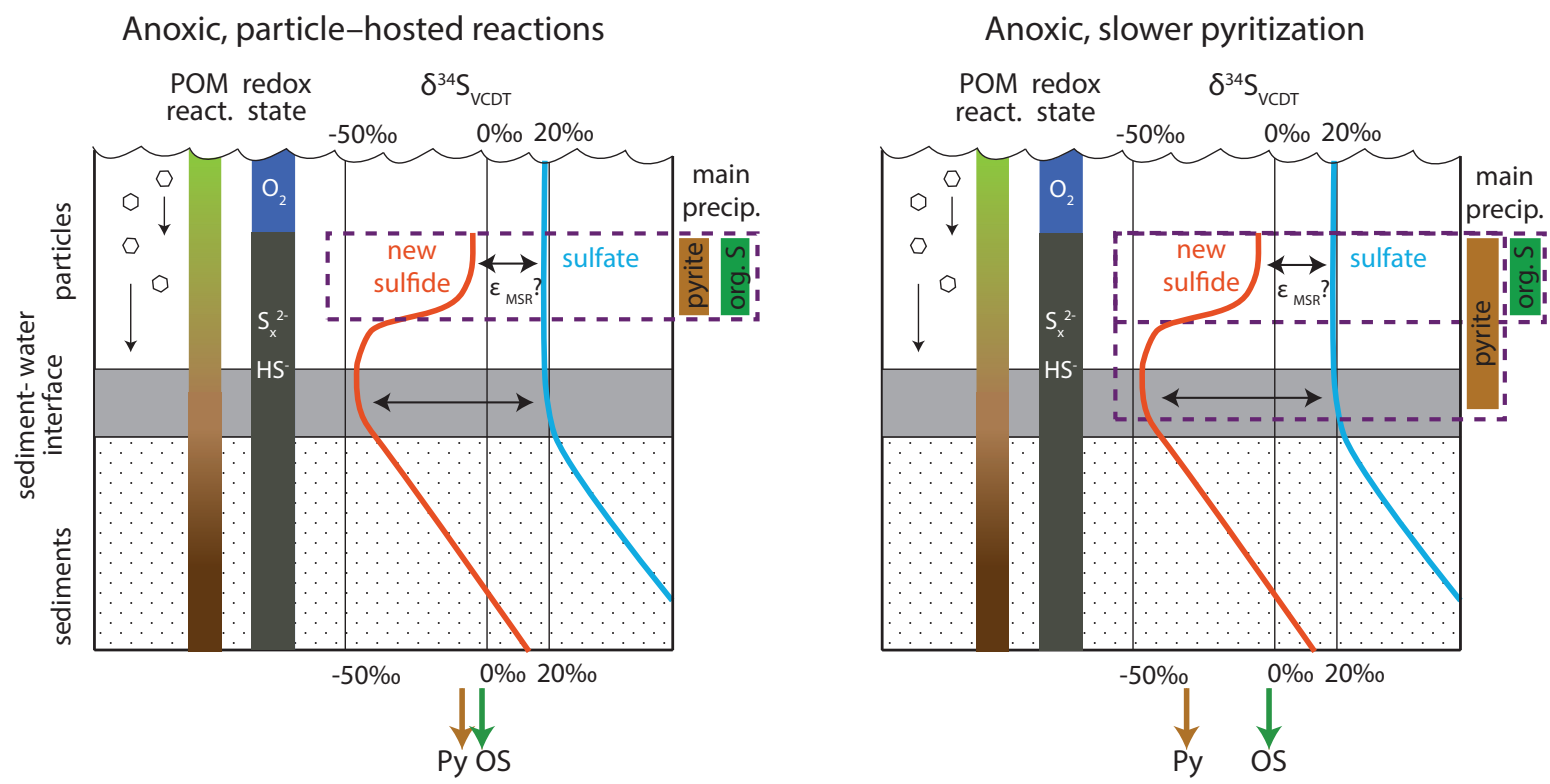

440 Fig. 9 Proposed model for OAE-2 $\delta^{34} \mathbf{S}$ records at Tarfaya and Demerara. Left panel

441 shows hypothesized conditions $\geq 190,000$ yrs before the onset of OAE-2. Right panel shows

442 a scenario for explaining pyrite and $\mathrm{OM} \delta^{34} \mathrm{~S}$ values during the early part of the OAE-2 C-

443 isotope excursion. Changes in available Fe could slow the rate of pyrite formation relative

444 to OM sulfurization and generate more ${ }^{34}$ S-depleted pyrite without impacting the S-isotope

445 composition of OM. The color scale labeled "POM react." represents a generalized decline

446 in the reactivity of particulate OM with age since export from the photic zone. Diagram is

447 not to scale.

449 Different processes impact $\delta^{34}$ S patterns at Tarfaya Basin and Demerara Rise. A wealth of

450 data supports the idea that the Tarfaya Basin and Demerara Rise water columns were

451 typically euxinic before and after OAE-2, which would imply open-system S cycling that

452 leads to ${ }^{34}$ S-depleted pyrite and OM (Hetzel et al., 2009; Poulton et al., 2015). Yet, $\delta^{34}$ S

453 values of pyrite and OM from both of these sites are near $-5 \%$ at these times, much more

$454{ }^{34}$ S-enriched than samples from other sites with open-system MSR. To reconcile these 
455 observations, we propose that the $\delta^{34} \mathrm{~S}$ values recorded in plentiful OM at Tarfaya Basin

456 and Demerara Rise do reflect the S-isotope composition of sulfide in sinking particles, and

457 that this sulfide was relatively ${ }^{34}$ S-enriched (Fig. 9; below). Similarly, there is limited

458 evidence for the existence of transiently ${ }^{34}$ S-enriched sulfide in particles from Cariaco

459 Basin during a period of peak productivity and sinking OM flux (Raven et al., 2016a).

460 Particles from this period contain abundant $\mathrm{C}_{20}$ thiophene, a common sulfurized

461 organosulfur compound, with a much more ${ }^{34}$ S-enriched composition ( -14.1 to $3.1 \%$ ) than

462 during other times ( -29.9 to $-18.2 \%$ ), indicating at least the transient existence of

463 relatively ${ }^{34}$ S-enriched (poly)sulfide in particles (Raven et al., 2016a) despite deep basin

464 sulfide $\delta^{34} \mathrm{~S}$ values near $-30 \%$ (Li et al., 2010). The dramatic increase in inferred sulfide

$465 \delta^{34} \mathrm{~S}$ values in particles from Cariaco Basin, Tarfaya Basin, and Demerara Rise (Fig. 9)

466 contrasts with the slight $(\sim 5 \%)$ increases in sulfide $\delta^{34} \mathrm{~S}$ value frequently observed in the

467 uppermost portion of modern sulfidic water columns (Lyons et al., 2003), which are

468 attributed to oxidative S-cycling microorganisms and/or abiotic sulfide oxidation. Thus,

469 the $\delta^{34} \mathrm{~S}$ values of strongly sulfurized OM and pyrite in TOC-rich sediments may capture

470 the signature of MSR occurring rapidly in sinking particles.

471

472 The large fluxes of fresh $\mathrm{OM}$ that reached $\mathrm{O}_{2}$-limited parts of the environment in both

473 Tarfaya Basin and Demerara Rise make these sites likely candidates for the operation of 474 rapid, substrate-replete MSR, which could lead to relatively ${ }^{34}$ S-enriched sulfide in

475 particles via smaller isotope fractionations during sulfate reduction, sulfate drawdown

476 within diffusively limited microenvironments, or both. The fractionation factor associated

477 with MSR ( $\left.\varepsilon_{\mathrm{MSR}}\right)$ is highly variable and depends broadly on MSR rate (Kaplan and 
478 Rittenberg, 1964). Although most marine systems have apparent S-isotope fractionation

479 factors closer to the equilibrium fractionation between sulfate and sulfide of $72 \%$, low $\varepsilon_{\text {MSR }}$

480 values $(<25 \%)$ are associated with high rates of cell-specific MSR, on the order of $>25$

$481 \mathrm{fmol} \mathrm{H}_{2} \mathrm{~S} /$ cell/day (Wenk et al., 2017), observed for sulfate reducers in laboratory settings

482 with plentiful carbon substrates and nutrients. These "small" S-isotope fractionations are

483 consistent with the 20-30\% difference between seawater sulfate (at $19 \%$ ) and apparent

484 particle-hosted sulfide observed at Tarfaya Basin and Demerara Rise. Alternatively or in 485 addition to changes in $\varepsilon_{\mathrm{MSR}}$, if particles are sufficiently large $(>>1 \mathrm{~mm})$, it is possible for

486 sulfate to become diffusively limited within particle microenvironments (Louca and 487 Crowe, 2017), especially given relatively low seawater sulfate concentrations at this time 488 (Lowenstein et al., 2003; Owens et al., 2013; Gomes et al., 2016). Very high rates of MSR 489 could therefore drive the remaining sulfate pool within microenvironments toward higher $490 \quad \delta^{34} \mathrm{~S}$ values and contribute to relatively ${ }^{34} \mathrm{~S}$-enriched sulfide.

492 The alternative explanation for our results attributes the relatively ${ }^{34}$ S-enriched 493 composition of pyrite and OM at Tarfaya Basin and Demerara Rise prior to the onset of 494 the OAE to their formation from sediment porewater. Importantly, it also requires that these 495 phases form semi-continuously during burial to the depths at which sulfate is nearly fully 496 drawn down, to integrate to bulk compositions near -5\%. Barring extreme sedimentation 497 events, this implies maximum OM sulfurization rates on the timescales of at least tens to 498 hundreds of years - sufficient to accumulate a diffusively limiting layer - not the days to 499 weeks observed in Cariaco particles and laboratory experiments. Additionally, this 500 explanation for Tarfaya Basin and Demerara Rise $\delta^{34} S$ patterns is difficult to reconcile with 
501 the S:C ratio of OM. For OM to incorporate up to $6 \mathrm{~mol} \% \mathrm{~S}$ gradually over at least years

502 of aging, that $\mathrm{OM}$ must have retained a high density of sulfurizable moieties that were

503 somehow also effectively inaccessible to heterotrophs. Theoretically, this could result from

504 enhanced preservation mechanisms other than sulfurization, notably physical protection by

505 association with clays or other mineral surfaces (Hedges and Keil, 1995) or the absence of

506 bioturbating macrofauna (Middelburg and Levin, 2009). Still, the sheer abundance of OM

507 in Tarfaya Basin and Demerara Rise sediments would overwhelm available clays, and it is

508 difficult to envision a mechanism to sulfurize OM after many years of effective physical

509 protection. We therefore consider a purely closed-system sedimentary origin for the

510 moderately ${ }^{34} \mathrm{~S}$-enriched OM at Tarfaya Basin and Demerara Rise improbable.

511

512 Similar to OM throughout the section, pyrite in the lowest part of the section at both

513 Tarfaya Basin and Demerara Rise has relatively high $\delta^{34} S$ values. Under these pre-OAE-2

514 conditions, the offset between pyrite and $\mathrm{OM} \delta^{34} \mathrm{~S}$ values is $5-10 \%$, similar to the offset

515 observed in other environments that are thought to host open-system concurrent

516 pyritization and OM sulfurization (Cariaco Basin, Cismon). Starting significantly before

517 the onset of OAE-2, pyrite $\delta^{34} \mathrm{~S}$ begins to move independently of OM $\delta^{34} \mathrm{~S}$, increasing

$518 \Delta \delta^{34}$ Sos-py values. Little-to-no concurrent shift is seen in the OM $\delta^{34} \mathrm{~S}$ record. Similarly,

519 XAS data show a lack of change in the speciation of organic S across the onset of OAE-2

520 at both Tarfaya Basin and Demerara Rise (Fig. 5), suggesting consistent conditions for OM

521 sulfurization throughout. Therefore, the shift in pyrite $\delta^{34} \mathrm{~S}$ values is caused by a process

522 that impacts the kinetics of one sulfide sink relative to the other, not by a change in sulfide

523 distribution or $\varepsilon_{\mathrm{MSR}}$ in the environment. In the case of pyrite at the onset of OAE-2 at 
524 Tarfaya and Demerara Rise, the observed shift indicates that the zone of pyrite formation

525 expanded into deeper portions of the water column and/or sediment, integrating more ${ }^{34} \mathrm{~S}-$

526 depleted sulfide generated from MSR at more typical (slow) environmental rates (Fig. 9)

527 for reasons we discuss below.

528

$529 \underline{4.3}$ Global pyrite $\delta^{34}$ S patterns and OAE-2 implications

530

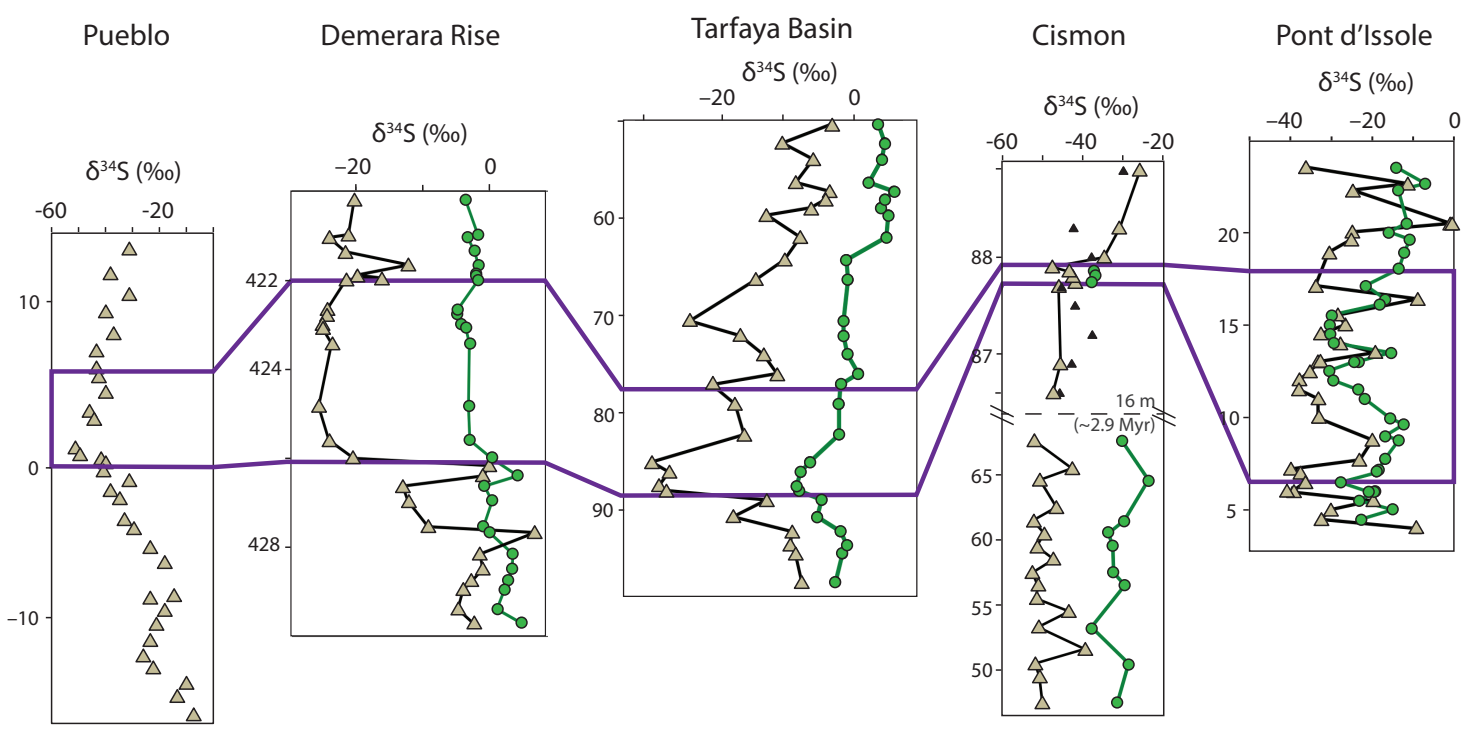

532 Fig. 10 Summary of $\delta^{34} \mathrm{~S}$ records across OAE-2. Green circles show $\mathrm{OM} \delta^{34} \mathrm{~S}$ values and

533 brown triangles show pyrite $\delta^{34} \mathrm{~S}$ values. Pueblo data are from Adams et al. (2010). The

534 gap in the Cismon y-axis represents $16 \mathrm{~m}$ of TOC-lean carbonates ( 2.9 Myr), and small

535 black triangles are previously published pyrite (CRS) data (Gomes et al., 2016). The C-

536 isotope excursion, representing an estimated $500 \mathrm{kyr}$ of accumulation, is outlined in purple.

537 Pyrites from Demerara Rise, Tarfaya Basin, and Pueblo all become more ${ }^{34} \mathrm{~S}$-depleted

538 leading up to the onset of OAE-2. 
540 The decrease in pyrite $\delta^{34} \mathrm{~S}$ values prior to the onset of OAE-2 appears to be a widespread

541 phenomenon, with remarkably similar profiles from Demerara Rise, Tarfaya Basin, and

542 the Western Interior Seaway (Pueblo; Adams et al., 2010). Because the 20\%o negative

$543 \delta^{34} \mathrm{~S}$ shift in pyrite at Tarfaya and Demerara is not observed in the $\delta^{34} \mathrm{~S}$ profile of OM, it is

544 not likely to primarily reflect changes in the spatial distribution or $\delta^{34} \mathrm{~S}$ of dissolved sulfide

545 in the environment. Instead, we propose that pyrite $\delta^{34}$ S patterns record changes in marine

546 iron supply across OAE-2, which impacted the kinetics of pyrite precipitation and extended

547 the zone of pyrite precipitation deeper in the sedimentary profile.

548

549 The highly reactive iron available for pyritization in marine environments is sourced from

550 a mixture of detrital iron from the continents, hydrothermal iron from spreading ridges, and

551 remobilized iron from biogeochemical cycling in shelf sediments (Poulton and Raiswell,

552 2002). Most sediments from the southern proto-North Atlantic during OAE-2 have

553 elevated $\mathrm{Fe}_{\mathrm{T}} / \mathrm{Al}$ ratios $\left(>0.5\right.$, the crustal average value) and near-zero $\delta^{56} \mathrm{Fe}$ compositions,

554 suggesting that a significant component of the iron delivered to these sites was from

555 hydrothermal sources (Owens et al., 2012). The processes that facilitate the transport of

556 hydrothermally sourced iron remain subjects of active research, but appear to involve

557 stabilization of $\mathrm{Fe}^{3+}$ in colloidal or nanoparticulate phases (Fitzsimmons et al., 2017).

558 Hydrothermal iron that encounters dissolved sulfide can precipitate as an Fe-sulfide and be

559 trapped in place as pyrite, restricting the amount of iron that can be transported through

560 euxinic basins to distal sites. In contrast, iron is highly mobile in anoxic but non-sulfidic

561 seawater. The delivery of iron to Demerara Rise and Tarfaya Basin was therefore likely 
562 sensitive to the redox state of nearby environments, and hydrothermal iron delivery could

563 have been significantly curtailed by nearby euxinia.

565 In addition to impacting the total flux of iron transported throughout the basin, expanding

566 anoxia is likely to affect its mineralogy. The source of Fe for pyritization is commonly

567 presumed to be dissolved $\mathrm{Fe}^{2+}$, which can be released from $\mathrm{Fe}^{\mathrm{III}}$-bearing minerals by

568 reduction either abiotically with bisulfide (Canfield, 1989) or biotically by Fe-reducing

569 microorganisms. The rates of both types of iron reduction vary depending on the

570 mineralogy and specific surface area of the $\mathrm{Fe}^{\mathrm{III}}$ involved: poorly crystalline oxyhydroxides

571 like ferrihydrite and lepidocrocite are reduced within hours to days, while crystalline oxides

572 and oxyhydroxides like goethite and hematite are reduced more slowly, and Fe-bearing

573 silicates can persist for millennia (Poulton and Canfield, 2005; Raiswell and Canfield,

574 1996). Where concentrations of $\mathrm{Fe}^{2+}$ and sulfide in solution are sufficiently high, pyrite

575 precipitation is generally thought to proceed via precipitation of an iron monosulfide

576 intermediate that subsequently converts to pyrite. Intriguingly, Wan et al. (2017) recently

577 described a second category of pyritization mechanism with the potential to drive pyrite

578 formation where $\mathrm{Fe}^{\mathrm{III}}$-oxide surfaces are plentiful and vastly exceed the available HS-

579 Under these conditions, ferric hydroxide surfaces can mediate the rapid nucleation of pyrite

580 via the formation of $>\mathrm{Fe}^{\mathrm{II}} \mathrm{S}_{2}{ }^{-}$, making redox interfaces and sinking particles with high

$581 \mathrm{Fe}^{\mathrm{IIII}}: \mathrm{HS}^{-}$ratios potential hotspots for surface-mediated pyritization of ferric hydroxides.

582 Expanding regional euxinia would likely reduce the transport of ferric hydroxides to

583 euxinic sites like Demerara Rise and Tarfaya Basin, lowering the $\mathrm{Fe}^{\mathrm{III}}: \mathrm{HS}^{-}$ratio near

584 critical interfaces in the water column. The resulting change in the relative importance of 
585 surface-mediated versus dissolved-phase pyritization mechanisms could thus contribute to

586 the observed shift in pyrite $\delta^{34} \mathrm{~S}$. Regardless of the significance of this particular

587 mechanism, changing regional redox could impact the mineralogy of remobilized Fe more

588 broadly by changing the rates and/or environmental conditions of (oxy)hydroxide

589 formation during repetitive redox cycling, generating a different suite of $\mathrm{Fe}^{\mathrm{IIII}}$ minerals that

590 re-release $\mathrm{Fe}^{2+}$ into the depositional environment at diverse rates. The bulk pyrite $\delta^{34} \mathrm{~S}$

591 records we present here reflect the integrated pool of pyrite derived from precipitation on

592 multiple timescales following $\mathrm{Fe}^{\mathrm{III}}$-mineral (re-)reduction as well as potentially from ferric

593 hydroxide surface-mediated reactions. Separating these various contributors to bulk pyrite

594 records will be essential for understanding how expanding regional anoxia and euxinia

595 impacted the abundance and mineralogy of iron sources and, by extension, the kinetics of

596 pyritization.

598 Trace metal concentrations and thallium isotopes from Demerara Rise provide evidence 599 for the expansion of regional to more global anoxia prior to the onset of the OAE-2 C600 isotope excursion (Ostrander et al., 2017; Owens et al., 2016). Like iron, the redox601 sensitive elements $\mathrm{Zn}, \mathrm{V}$, and Mo are readily sequestered in anoxic and/or sulfidic 602 sediments, and this process is thought to be responsible for their apparent removal from 603 seawater prior to OAE-2 (Owens et al., 2016). Using an extrapolation of the estimated 604 OAE-2 linear sedimentation rate $(0.8 \mathrm{~cm} / \mathrm{kyr})$ to $427.5 \mathrm{~m}$, pyrite $\delta^{34} \mathrm{~S}$ values at Demerara 605 begin to decrease $\sim 190 \mathrm{kyr}$ before the onset of OAE-2. This depth corresponds to the initial 606 drop in concentrations of $\mathrm{Zn}$ in this core, a sensitive indicator of anoxia with a short 607 residence time ( 11 kyr, Little et al., 2014) that implies a global increase in non-sulfidic, 
608 anoxic conditions significantly before the onset of OAE-2. The decrease in pyrite $\delta^{34} \mathrm{~S}$

609 values is complete by the onset of the OAE, in sediments evidencing drawdown of even

610 sulfide-sensitive Mo, indicating prevalent sulfidic environments (Owens et al., 2016). The

611 gradual pre-OAE pyrite $\delta^{34} \mathrm{~S}$ shift at Demerara thus corresponds to a period of

612 intensification of regional to global anoxia prior to the OAE and an expansion of sulfidic

613 conditions globally (Owens et al., 2013).

614

615 Changes in the delivery of iron to sites in the southern proto-North Atlantic could have 616 generated the shift in pyrite $\delta^{34} \mathrm{~S}$ that we observe by slowing the kinetics of pyrite

617 formation. For example, if the combination of expanding euxinia and volcanic activity 618 caused the main source of Fe at these sites to switch from more hydrothermally sourced, 619 organic-complexed $\mathrm{Fe}^{\mathrm{III}}$ to detrital or volcanic crystalline oxy-hydroxides, the rate of $\mathrm{Fe}^{2+}$ 620 release to solution in sinking marine particles could have dropped dramatically. The 621 conceptual model put forth in Fig. 9 predicts that this scenario would yield more ${ }^{34} \mathrm{~S}$ -

622 depleted pyrite overall. Importantly, this could occur while the total quantity of pyrite 623 eventually buried remained nearly constant.

625 At Pueblo and Tarfaya Basin, the onset of the shift toward more ${ }^{34} \mathrm{~S}$-depleted pyrite is 626 staggered relative to Demerara Rise (Fig. 10). Using published interpolated Ar-Ar ages 627 from ammonite biozones, pyrite $\delta^{34} \mathrm{~S}$ values at Pueblo drop in two stages at $\sim 400 \mathrm{kyr}$ and $628 \sim 200$ kyr before the onset of OAE-2 (Adams et al., 2010). At Tarfaya Basin, if we 629 extrapolate estimated OAE-2 accumulation rates $(3.3 \mathrm{~cm} / \mathrm{kyr})$ similar to Demerara, then 630 the pyrite $\delta^{34} \mathrm{~S}$ shift occurs $\sim 82 \mathrm{kyr}$ before the OAE. Osmium, strontium, and other 
631 geochemical proxies indicate regional heterogeneity in hydrothermal activity in different

632 ocean basins at this time (du Vivier et al., 2014), which would also impact hydrothermal

633 iron fluxes (Owens et al., 2012). Importantly, the Western Interior Seaway has a different

634 redox structure leading up to OAE-2 than the rest of the proto-North Atlantic and Tethys,

635 which likely leads to differences in the history of iron cycling among these sites.

636

637 Records from OAE-2 exemplify how the timing and location of pyritization can be affected

638 by changes in iron supply in addition to changes in sulfur cycling. They also suggest that

639 organic S should be incorporated into future models for the $\mathrm{S}$ cycle for OAEs. For example,

640 because organic $\mathrm{S}$ is more typically more ${ }^{34} \mathrm{~S}$-enriched than pyrite, previous estimates for

641 the extent of euxinia during OAE-2 based on S-isotope mass balance (e.g., Owens et al.,

642 2013) may be conservative. OM sulfurization could have been an important factor for

643 driving high organic carbon mass accumulation rates even for localities with low TOC

644 (Owens et al., 2018), supporting massive global OM burial. By investigating the S-isotope

645 behavior of both pyrite and OM, we can begin to take full advantage of these complex and 646 powerful archives.

\section{5. Conclusions}

649 Rapid, particle-hosted OM sulfurization may have been a central process facilitating 650 enhanced OM preservation across large swaths of the Tethys and North Atlantic Oceans 651 before, during, and after OAE-2. Explicit consideration of rapid $\mathrm{OM}$ sulfurization in $\mathrm{O}_{2}$ 652 limited environments thus has the potential to improve models of TOC preservation and 653 remineralization in both modern and ancient systems. 
655 Paired OM and pyrite $\delta^{34} \mathrm{~S}$ profiles make it possible to disentangle the effects of chemocline 656 position, sulfate reduction rate, and regional-to-global geochemical perturbations on S657 isotopes in the rock record. In the several hundred thousand years leading up to the onset 658 of $\mathrm{OAE}-2$, pyrite and $\mathrm{OM} \delta^{34} \mathrm{~S}$ records indicate a globally widespread change in the timing 659 of pyrite formation relative to OM sulfurization, which both S-isotope and speciation 660 (XAS) data argue occurred consistently across this interval. A regional expansion of 661 euxinic conditions and changes in volcanic activity may have contributed to changes in the 662 speciation of iron available for pyritization and thus to the relatively slow formation of

663 relatively ${ }^{34} \mathrm{~S}$-depleted pyrite during the OAE. This change in global iron cycling could not

664 be identified from pyrite $\delta^{34} S$ profiles alone, underscoring the value and untapped potential 665 of paired pyrite - OM S-isotope records for exploring the geologic record.

\section{Acknowledgements}

669 We are grateful for financial support to M.R.R. from the Agouron Institute (Geobiology 670 Post-doctoral Fellowship) and to Itay Halevy (Weizmann Institute, Israel), Matt Hurtgen, 671 and Brad Sageman (Northwestern University, USA) for valuable discussions. Melanie 672 Suess, Jen Houghton, and Stephanie Moore provided technical support for analyses at 673 Washington University in St. Louis. Tarfaya and Demerara samples were obtained via 674 Wolfgang Kuhnt (Kiel University) and IODP, respectively. Virgil Pasquier (Weizmann 675 Institute, Israel) provided Gulf of Lion samples. JDO would like to acknowledge support 676 from NASA Exobiology (80NSSC18K1532). This work was enhanced by XAS analyses 
677 at the Stanford Synchrotron Radiation Laboratory under User Proposal 4885, as well as by 678 the efforts of SSRL staff. Use of the Stanford Synchrotron Radiation Lightsource, SLAC

679 National Accelerator Laboratory, is supported by the U.S. Department of Energy, Office 680 of Science, Office of Basic Energy Sciences under Contract No. DE-AC02-76SF00515. 681 682 Supplemental Information:

683 Fig. S1: whole-rock basis version of Fig. 6

684 Table S1: Average relative abundances of organic S moieties for sections spanning OAE6852 by XAS

686 Table S2: Gulf of Lion average composition

687 Table S3: Compiled geochemical results

688 Table S4: Compiled XAS results

689 
690

691

692

693

694

695

696

697

698

699

700

701

702

703

704

705

706

707

708

709

710

711

712

713

714

715

716

717

718

719

720

721

722

723

724

725

726

727

728

729

730

\section{References}

Adams, D.D., Hurtgen, M.T., Sageman, B.B., 2010. Volcanic triggering of a biogeochemical cascade during Oceanic Anoxic Event 2. Nature Geoscience 3, $201-$ 204.

Amrani, A., Aizenshtat, Z., 2004. Mechanisms of sulfur introduction chemically controlled: $834 \mathrm{~S}$ imprint. Organic Geochemistry 35, 1319-1336. doi:10.1016/j.orggeochem.2004.06.019

Anderson, T.F., Pratt, L.M., 1995. Isotopic evidence for the origin of organic sulfur and elemental sulfur in marine sediments. In: Geochemical Transformations of Sedimentary Sulfur. ACS Symposium Series, vol. 612, 378-396. American Chemical Society, Washington DC.

Bellanca, A., Claps, M., Erba, E., Masetti, D., Neri, R., 1996. Orbitally induced limestone/marlstone rhythms in the Albian-Cenomanian Cismon section (Venetian region, northern Italy): Sedimentology, calcareous and siliceous plankton distribution, elemental and isotope geochemistry. Palaeogeography 126, 227-260. doi:10.1016/S0031-0182(96)00041-7

Blair, N.E., Aller, R.C., 2012. The Fate of Terrestrial Organic Carbon in the Marine Environment. Annu. Rev. Mar. Sci. 4, 401-423.

Boussafir, M., Gelin, F., Lallier-Verges, E., Derenne, S., Bertrand, P., Largeau, C., 1995. Electron microscopy and pyrolysis of kerogens from the Kimmeridge Clay Formation, UK: Source organisms, preservation processes, and origin of microcycles. Geochimica et Cosmochimica Acta 59, 3731-3747.

Canfield, D.E., 1989. Reactive iron in marine sediments. Geochimica et Cosmochimica Acta 53, 619-632. doi:10.1016/0016-7037(89)90005-7

Canfield, D.E., Raiswell, R., Westrich, J.T., Reaves, C.M., 1986. The use of chromium reduction in the analysis of reduced inorganic sulfur in sediments and shales. Chemical Geology 54, 149-155.

Dale, A.W., Bruchert, V., Alperin, M., Regnier, P., 2009. An integrated sulfur isotope model for Namibian shelf sediments. Geochimica et Cosmochimica Acta 73, 19241944. doi:10.1016/j.gca.2008.12.015

du Vivier, A.D.C., Selby, D., Sageman, B.B., Jarvis, I., Gröcke, D.R., Voigt, S., 2014. Marine $187 \mathrm{Os} / 188 \mathrm{Os}$ isotope stratigraphy reveals the interaction of volcanism and ocean circulation during Oceanic Anoxic Event 2. Earth and Planetary Science Letters 389, 23-33. doi:10.1016/j.eps1.2013.12.024

Eglinton, T.I., Irvine, J.E., Vairavamurthy, A., Zhou, W., Manowitz, B., 1994. Formation and diagenesis of macromolecular organic sulfur in Peru margin sediments. Organic Geochemistry 22, 781-799. doi:10.1016/0146-6380(94)90139-2

Erbacher, J., Friedrich, O., Wilson, P.A., Birch, H., Mutterlose, J., 2005. Stable organic carbon isotope stratigraphy across Oceanic Anoxic Event 2 of Demerara Rise, western tropical Atlantic. Geochemistry Geophysics Geosystems 6, 714-9. doi: $10.1029 / 2004 \mathrm{GC} 000850$ 
731 Fike, D.A., Grotzinger, J.P., 2008. A paired sulfate-pyrite $\delta 34$ S approach to understanding the evolution of the Ediacaran-Cambrian sulfur cycle. Geochimica et Cosmochimica Acta 72, 2636-2648. doi:10.1016/j.gca.2008.03.021

Fitzsimmons, J.N., John, S.G., Marsay, C.M., Hoffman, C.L., Nicholas, S.L., Toner, B.M., German, C.R., Sherrell, R.M., 2017. Iron persistence in a distal hydrothermal plume supported by dissolved-particulate exchange. Nature Geosci 10, 195-201. doi:10.1038/ngeo2900

Francois, R. (1987). A study of sulphur enrichment in the humic fraction of marine sediments during early diagenesis. Geochimica Et Cosmochimica Acta, 51, 17-27.

Friedrich, O., Erbacher, J., Wilson, P. A., Moriya, K., \& Mutterlose, J. (2009). Paleoenvironmental changes across the Mid Cenomanian Event in the tropical Atlantic Ocean (Demerara Rise, ODP Leg 207) inferred from benthic foraminiferal assemblages. Marine Micropaleontology, 71(1-2), 28-40. http://doi.org/10.1016/j.marmicro.2009.01.002

Gambacorta, G., Jenkyns, H.C., Russo, F., Tsikos, H., Wilson, P.A., Faucher, G., Erba, E., 2015. Carbon- and oxygen-isotope records of mid-Cretaceous Tethyan pelagic sequences from the Umbria - Marche and Belluno Basins (Italy). Newsl. Stratigr. 48, 299-323. doi:10.1127/nos/2015/0066

Gelin, F., Kok, M.D., De Leeuw, J.W., Sinninghe Damsté, J.S., 1998. Laboratory sulfurisation of the marine microalga Nannochloropsis salina. Organic Geochemistry 29, 1837-1848.

Gomes, M.L., Hurtgen, M.T., Sageman, B.B., 2016. Biogeochemical sulfur cycling during Cretaceous oceanic anoxic events: A comparison of OAE1a and OAE2. Paleoceanography 1-19. doi:10.1002/(ISSN)1944-9186

Hedges, J., \& Keil, R. (1995). Sedimentary organic matter preservation: an assessment and speculative synthesis. Marine Chemistry, 49, 81-115.

Hedges, J.I., Hu, F.S., Devol, A.H., Hartnett, H.E., Tsamakis, E., Keil, R.G., 1999. Sedimentary organic matter preservation; a test for selective degradation under oxic conditions. American Journal of Science 299, 529-555.

Hetzel, A., Böttcher, M.E., Wortmann, U.G., Brumsack, H.-J., 2009. Paleo-redox conditions during OAE 2 reflected in Demerara Rise sediment geochemistry (ODP Leg 207). Palaeogeography, Palaeoclimatology, Palaeoecology 273, 302-328. doi:10.1016/j.palaeo.2008.11.005

Jarvis, I., Lignum, J.S., Gröcke, D.R., Jenkyns, H.C., 2011. Black shale deposition, atmospheric $\mathrm{CO} 2$ drawdown, and cooling during the Cenomanian-Turonian Oceanic Anoxic Event. Paleoceanography 26. doi:10.1029/2010PA002081

Jorgensen, B.B., 1979. A theoretical model of the stable sulfur isotope distribution in marine sediments. Geochimica et Cosmochimica Acta 43, 363-374.

Kaplan, I.R., Rittenberg, S.C., 1964. Microbiological fractionation of sulphur isotopes. Journal of General Microbiology 34, 195-212. 
Keller, G., Adatte, T., Berner, Z., Chellai, E.H., Stueben, D., 2008. Oceanic events and biotic effects of the Cenomanian-Turonian anoxic event, Tarfaya Basin, Morocco. Cretaceous Research 29, 976-994. doi:10.1016/j.cretres.2008.05.020

Kolonic, S., Damsté, J., Böttcher, M.E., Kuypers, M.M.M., Kuhnt, W., Scheeder, G., Wagner, T., beckmann, B., 2002. Geochemical characterization of Cenomanian/Turonian black shales from the Tarfaya Basin (SW Morocco). Journal of Petroleum Geology 25, 325-350.

Kolonic, S., Wagner, T., Forster, A., Sinninghe Damsté, J.S., Walsworth-Bell, B., Erba, E., Turgeon, S., Brumsack, H.-J., Chellai, E.H., Tsikos, H., Kuhnt, W., Kuypers, M.M.M., 2005. Black shale deposition on the northwest African Shelf during the Cenomanian/Turonian oceanic anoxic event: Climate coupling and global organic carbon burial. Paleoceanography 20, 1-18. doi:10.1029/2003PA000950

Kuypers, M.M.M., Pancost, R.D., Nijenhuis, I.A., Sinninghe Damsté, J.S., 2002. Enhanced productivity led to increased organic carbon burial in the euxinic North Atlantic basin during the late Cenomanian oceanic anoxic event. Paleoceanography 17, 1-13. doi:10.1029/2000PA000569

Li, X., Gilhooly, W.P., III, Zerkle, A.L., Lyons, T.W., Farquhar, J., Werne, J.P., Varela, R., Scranton, M.I., 2010. Stable sulfur isotopes in the water column of the Cariaco Basin. Geochimica et Cosmochimica Acta 74, 6764-6778. doi:10.1016/j.gca.2010.08.020

Little, S.H., Vance, D., Walker-Brown, C., Landing, W.M., 2014. The oceanic mass balance of copper and zinc isotopes, investigated by analysis of their inputs, and outputs to ferromanganese oxide sediments. Geochimica et Cosmochimica Acta 125, 673-693. doi:10.1016/j.gca.2013.07.046

Louca, S., Crowe, S.A., 2017. Microscale reservoir effects on microbial sulfur isotope fractionation. Geochimica et Cosmochimica Acta 203, 117-139. doi:10.1016/j.gca.2017.01.007

Lowenstein, T.K., Hardie, L.A., Timofeeff, M.N., Demicco, R.V., 2003. Secular variation in seawater chemistry and the origin of calcium chloride basinal brines. Geology 31, 857-860. doi:10.1130/G19728R.1

Lyons, T.W., Werne, J.P., Hollander, D.J., Murray, R.W., 2003. Contrasting sulfur geochemistry and $\mathrm{Fe} / \mathrm{Al}$ and $\mathrm{Mo} / \mathrm{Al}$ ratios across the last oxic-to-anoxic transition in the Cariaco Basin, Venezuela. Chemical Geology 195, 131-157. doi:10.1016/S00092541(02)00392-3

Middelburg, J.J., Levin, L.A., 2009. Coastal hypoxia and sediment biogeochemistry. Biogeosciences 6, 1273-1293. doi:10.5194/bg-6-1273-2009

Ostrander, C.M., Owens, J.D., Nielsen, S.G., 2017. Constraining the rate of oceanic deoxygenation leading up to a Cretaceous Oceanic Anoxic Event (OAE-2: 94 Ma). Science Advances 3, 1-6.

Owens, J.D., Gill, B.C., Jenkyns, H.C., 2013. Sulfur isotopes track the global extent and dynamics of euxinia during Cretaceous Oceanic Anoxic Event 2. Proceedings of the National Academy of Sciences 110, 18407-18412. 
813 Owens, J.D., Lyons, T.W., Li, X., Macleod, K.G., 2012. Iron isotope and trace metal

814

815

816

817

818

819

820

821

822

823

824

825

826

827

828

829

830

831

832

833

834

835

836

837

838

839

840

841

842

843

844

845

846

847

848

849

850

851

852 records of iron cycling in the proto North Atlantic during the Cenomanian Turonian oceanic anoxic event (OAE 2). Paleoceanography. doi:10.1029/2012PA002328

Owens, J.D., Lyons, T.W., Lowery, C.M., 2018. Quantifying the missing sink for global organic carbon burial during a Cretaceous oceanic anoxic event. Earth and Planetary Science Letters 499, 83-94. doi:10.1016/j.eps1.2018.07.021

Owens, J.D., Reinhard, C.T., Rohrssen, M., Love, G.D., Lyons, T.W., 2016. Empirical links between trace metal cycling and marine microbial ecology during a large perturbation to Earth's carbon cycle. Earth and Planetary Science Letters 449, 407417. doi:10.1016/j.eps1.2016.05.046

Pohlabeln, A.M., Gomez-Saez, G.V., Noriega-Ortega, B.E., Dittmar, T., 2017. Experimental Evidence for Abiotic Sulfurization of Marine Dissolved Organic Matter. Frontiers in Marine Sci. 4, 265. doi:10.3389/fmars.2017.00364

Poulton, S., Canfield, D., 2005. Development of a sequential extraction procedure for iron: implications for iron partitioning in continentally derived particulates. Chemical Geology 214, 209-221. doi:10.1016/j.chemgeo.2004.09.003

Poulton, S.W., Henkel, S., März, C., Urquhart, H., Flögel, S., Kasten, S., Sinninghe Damsté, J.S., Wagner, T., 2015. A continental-weathering control on orbitally driven redox-nutrient cycling during Cretaceous Oceanic Anoxic Event 2. Geology 43, 963966. doi:10.1130/G36837.1

Poulton, S.W., Raiswell, R., 2002. The low-temperature geochemical cycle of iron: From continental fluxes to marine sediment deposition. American Journal of Science 302, 774-805. doi:10.2475/ajs.302.9.774

Raiswell, R., Canfield, D.E., 1996. Rates of reaction between silicate iron and dissolved sulfide in Peru Margin sediments. Geochimica et Cosmochimica Acta 60, 27772787.

Raven, M.R., Fike, D.A., Gomes, M.L., Webb, S.M., Bradley, A.S., McClelland, H.L.O., 2018. Organic carbon burial during OAE2 driven by changes in the locus of organic matter sulfurization. Nature Communications 9, 3409. doi:10.1038/s41467018-05943-6

Raven, M.R., Sessions, A.L., Adkins, J.F., Thunell, R.C., 2016a. Rapid organic matter sulfurization in sinking particles from the Cariaco Basin water column. Geochimica et Cosmochimica Acta 190, 175-190. doi:10.1016/j.gca.2016.06.030

Raven, M.R., Sessions, A.L., Fischer, W.W., Adkins, J.F., 2016b. Sedimentary pyrite $\delta$ $34 \mathrm{~S}$ differs from porewater sulfide in Santa Barbara Basin: Proposed role of organic sulfur. Geochimica et Cosmochimica Acta 186, 120-134.

doi:10.1016/j.gca.2016.04.037

Sageman, B.B., Meyers, S.R., Arthur, M.A., 2006. Orbital time scale and new C-isotope record for Cenomanian-Turonian boundary stratotype. Geology 34, 125-4.

doi:10.1130/G22074.1 
853 Sinninghe Damsté, J.S., Köster, J., 1998. A euxinic southern North Atlantic Ocean during

854 the Cenomanian/Turonian oceanic anoxic event. Geochimica et Cosmochimica Acta

$855158,165-173$.

856 Vairavamurthy, A., 1998. Using X-ray absorption to probe sulfur oxidation states in

857 complex molecules. Spectrochimica Acta Part A 54, 2009-2017. doi:10.1016/S1386-

$858 \quad 1425(98) 00153-X$

859 van Dongen, B.E., Schouten, S., Baas, M., Geenevasen, J.A.J., Sinninghe Damsté, J.S.,

860 2003. An experimental study of the low-temperature sulfurization of carbohydrates.

861 Organic Geochemistry 34, 1129-1144. doi:10.1016/S0146-6380(03)00060-3

862 Wan, M., Schröder, C., Peiffer, S., 2017. Fe (III): S (-II) Concentration Ratio Controls the

863 Pathway and the Kinetics of Pyrite Formation during Sulfidation of Ferric

864 Hydroxides. Geochimica et Cosmochimica Acta. doi:10.1016/j.gca.2017.08.036

865 Webb, S.M., 2005. SIXpack: a graphical user interface for XAS analysis using IFEFFIT.

866 Phys. Scr. 2005, 1011. doi:10.1238/Physica.Topical.115a01011

867 Wenk, C.B., Wing, B.A., Halevy, I., 2017. Electron carriers in microbial sulfate reduction

868 inferred from experimental and environmental sulfur isotope fractionations. The

869 ISME Journal 12, 1-13. doi:10.1038/ismej.2017.185

870 Werne, J., Lyons, T., Hollander, D., Schouten, S., Hopmans, E., \& Damste, J. (2008).

871 Investigating pathways of diagenetic organic matter sulfurization using compound-

872 specific sulfur isotope analysis. Geochimica Et Cosmochimica Acta, 72, 3489-3502.

873 Werne, J.P., Lyons, T.W., Hollander, D.J., Chemical, M.F., Sinninghe Damsté, J.S.,

874 2003. Reduced sulfur in euxinic sediments of the Cariaco Basin: sulfur isotope

875 constraints on organic sulfur formation. Geochimica et Cosmochimica Acta 195,

876 159-179. doi:10.1016/S0009-2541(02)00393-5

877 